\title{
ANFIBÓLIOS DO CORPO ANFIBOLÍTICO DO JARAGUÁ, SP
}

\author{
CELSO DE BARROS GOMES*
}

MARIE CLAIRE VAN OOSTERWYGK-GASTUCHE**

CLÁUDIO VIEIRA DUTRA***

\begin{abstract}
As a consequence of rising temperature, probably caused by the Cantareira granitic intrusion, the Jaraguá amphibolites have suffered changes in petrographic and chemical composition. Although no complete equilibrium has been attained, they did respond sufficiently to the new metamorphic conditions as indicated by very diagnostic mineralogical and textural features.

For the amphiboles, the petrographic evidences have been made up of an increase in grain size in addition to the recrystallization with the crystals showing granoblastic shape and poiquiloblastic texture, as well as the actinolite breakdown into hornblende. The chemical evidences have mainly consisted of a slight aluminum and titanium enrichment.
\end{abstract}

INTRODUC̣Ão Face o caráter singular de sua mineralogia e textura, o corpo anfibolítico ocorrendo na região do Jaraguá, distante aproximadamente $22 \mathrm{~km}$ a noroeste da cidade de São Paulo, tem merecido a atenção de diversos pesquisadores. Coube a Gomes (1962) estudá-lo mais detidamente com vistas à sua melhor caracterização mineralógico-petrográfica, bem como coligir dados que pudessem contribuir com a interpretação de sua gênese. Após reunir apreciável acervo de informações químicas, Gomes et al. (1964) procederam à discussão do quimismo e origem desses anfibolitos, chegando à conclusão de que, geneticamente, os mesmos teriam sido derivados do metamorfismo dinamotermal de antigas rochas básicas intrusivas no pacote metassedimentar. Embora contando apenas com dados ópticos e evidências texturais, esses autores teceram também alguns comentários a respeito das possíveis mudanças químicas que teriam se processado nos minerais das rochas anfibolíticas, como resultado de variações do gradiente térmico regional. Algumas considerações preliminares sobre o quimismo dos anfibólios foram feitas por Gomes et al. (1968).

Mais recentemente, Gomes (1971) investigou o comportamento químico dos minerais mais importantes dessas rochas, tendo em mente uma melhor compreensão dos fenômenos sucedidos no interior do corpo anfibolítico. Uma análise pormenorizada do comportamento dos plagioclásios é fornecida em Gomes (no prelo).

O presente trabalho, extraído inteiramente da publicação inédita de Gomes (1971) e tratando especificamente dos anfibólios, visa estabelecer, com bases em resultados analíticos, as principais variações químicas que ocorreram nesses minerais e que, tentativamente, a partir de dados ópticos, haviam sido sugeridas por Gomes (1962) e Gomes et al. (1964), bem como discuti-las como evidências indicativas de modificações ocorridas nas condições de pressão e temperatura reinantes no corpo anfibolítico.

\footnotetext{
*Instituto de Geociências, Universidade de São Paulo, Caixa Postal 20 899, São Paulo

**Musée Royal de l'Afrique Centrale, Tervuren, Bélgica

***Instituto de Tecnologia Industrial, Belo Horizonte
} 
Geologia local Os anfibolitos investigados, constituindo um corpo único com dimensões aproximadas de 1,5 por $2,5 \mathrm{~km}$, ocorrem na região do Jaraguá, associados, principalmente, a metassedimentos do Grupo São Roque, localmente representados por sericita xistos e quartzitos (Fig. 1). Esse corpo dispõe-se em aparente discordância com respeito à estrutura regional, além de mostrar-se confinado, junto à sua porção $\mathrm{SE}$, por extensa massa granítica, tipo Pirituba, de idade posterior às demais rochas da área. Sedimentos recentes, formando várzeas e depósitos de tálus, foram também assinalados na região.

A área do Jaraguá foi afetada por intenso e complexo falhamento, possuindo os sistemas principais direções dominantes N45W e N25E. Nos quartzitos e sericita xistos, parece existir uma estrutura sinclinal de eixo aproximadamente E-W, com inclinação moderada para W. Os anfibolitos estariam localizados na crista desse sinclinal (Cordani et. al., 1961).

Métodos de trabalho Técnicas de análise química A determinação da composição química dos anfibólios processou-se com o auxílio das técnicas da microssonda eletrônica, fluorescência de raios X e espectrografia óptica.

O programa com a microssonda foi executado pelo primeiro autor nos laboratórios do Departamento de Geologia e Geofísica da Universidade da Califórnia, Berkeley, Estados Unidos da América. O instrumento usado foi um Electron Probe Microanalyzer, modelo EMX-SM, de fabricação ARL, equipado com três espectrômetros dispersivos e três pares de cristais (LiF/ADP, LiF/ADP e LiF/KAP). Os dados analíticos obtidos foram corrigidos para background, drift, número atômico, fluorescência secundária e absorção atômica, usando-se o programa de computação elaborada por Frazer et al. (1966). A correção para dead time foi sempre eliminada, mantendo-se a contagem abaixo de $5000 \mathrm{c} / \mathrm{s}$.

Excluindo-se os valores de $\mathrm{Cl}$ e $\mathrm{F}$, os demais dados fornecidos nas tabelas correspondem a uma média aritmética de cerca de 15 a 25 determinações em grânulos diferentes da mesma espécie mineralógica para cada amostra investigada. A fim de ter-se um controle mais rigoroso dos resultados, as determinações foram sempre processadas em duplicata. No caso particular daqueles elementos, o valor médio foi obtido a partir de apenas dez determinações. O número total de amostras de rochas investigadas foi vinte e três. A análise estatística dos resultados por meio do desvio-padrão permitiu estimar a precisão, para os elementos mais abundantes, em torno de $5 \%$ e, ao redor de $10 \%$, para os presentes em porcentagens diminutas.

Excetuando-se Cl e F, todos os demais elementos foram dosados com o aparelho operando nas seguintes condições: intensidade de corrente, 0,05-0,08 $\mathrm{mA}$; potencial de aceleração, $15 \mathrm{kV}$; tempo de integração, 15", e diâmetro aproximado do feixe eletrônico, $1 \mu$. No caso dos dois elementos citados, as condições foram, respectivamente, as que se seguem: 0,15-0,20 mA, $10 \mathrm{kV}, 50^{\prime \prime}$ e $15 \mu$.

Como padrões foram utilizados tão-somente cristais naturais, a saber: kaersutita (Brown e Carmichael, 1969) para $\mathrm{Si}, \mathrm{Ti}, \mathrm{Al}, \mathrm{Fe}, \mathrm{Mg}$ e $\mathrm{Ca}$; biotita ${ }^{\circ}{ }^{\circ} 3$ para $\mathrm{K}$; cummingtonita n. 8 para Mn; jadeíta n. ${ }^{\circ} 3$ (Coleman, 1961) para $\mathrm{Na}$; escapolita n. 16 (Shaw, 1960) para Cl e flogopita n. 7 (Rimsaite, 1964) para F.

$\mathrm{O}$ trabalho analítico com a fluorescência de raios $\mathrm{X}$, consistindo da determinação da composição química de dez concentrados de anfibólios, foi executado por M. C. Van Oosterwyck-Gastuche, nos laboratórios do Musée Royal de l'Afrique Centrale, Tervuren, Bélgica. Os concentrados usados, variando em peso de 5 a $10 \mathrm{~g}$, foram obtidos com o auxílio de um separador eletromagnético, modelo Frantz, e líquidos pesados (solução de Clerici). A sua pureza é estimada como sendo não inferior a $95 \%$. Como padrão analítico, utilizou-se a rocha BCR-1 (United States Geological Survey), com dados fornecidos por Flanagan 


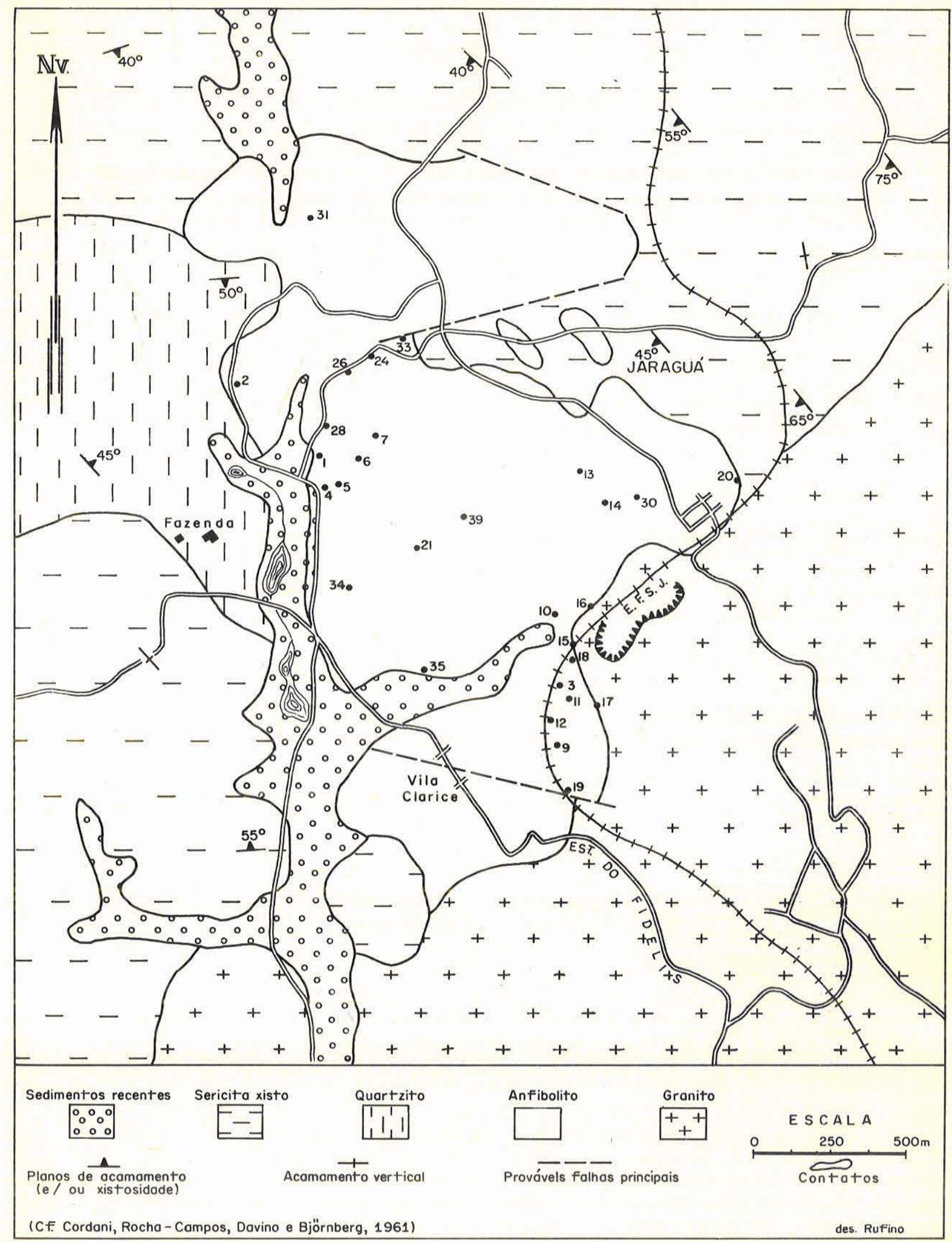

Figura 1 - Mapa geológico da área do Jaraguá, com localização das amostras investigadas 
(1967). Os teores de $\mathrm{FeO}$ e $\mathrm{MgO}$ foram, contudo, determinados pelos métodos químicos convencionais, o mesmo sucedendo com $\mathrm{H}_{2} \mathrm{O}^{+}$e $\mathrm{H}_{2} \mathrm{O}^{-}$.

Os elementos-traços das dez amostras de concentrados de anfibólios, analisados para seus elementos principais por fluorescência de raios $\mathrm{X}$, foram determinados por Cláudio V. Dutra, do Instituto de Tecnologia Industrial, Belo Horizonte, por métodos espectrográficos sem uso de padrões internos. Informações sobre as características do instrumento utilizado, bem como acerca do procedimento analítico adotado, são encontradas em Herz e Dutra (1960).

Fórmula química dos anfibólios $\mathrm{O}$ cálculo da fórmula, a partir dos dados constantes das diversas tabelas, seguiu, em traços gerais, o procedimento adotado por Warren (1930). Contudo, como unidade de cálculo para o número de átomos de oxigênio referente à metade da cela unitária, tomou-se seja 23, seja 24.

O motivo da utilização de uma base de cálculo de 23 para os anfibólios das Tabs. VII e IX prende-se à não-determinação da água de cristalização pelo método da microssonda. Esse procedimento de cálculo foi formalmente sugerido por Binns (1965), tendo-se em vista as freqüentes imprecisões que se verificam na determinação de $\mathrm{H}_{2} \mathrm{O}^{+}$, aliada à omissão da análise de $\mathrm{F}$, nesses minerais, levando, conseqüentemente, à introdução de erros substanciais na fórmula química, uma vez calculada na base de $24(\mathrm{O}, \mathrm{OH}, \mathrm{F}, \mathrm{Cl})$.

Outro aspecto ligado à composição desses minerais prende-se à valência do ferro para os dados conseguidos com o auxílio da microssonda. Assumiu-se, de conformidade com dados de literatura, que esse elemento ocorre preferencialmente na forma de $\mathrm{FeO}$ nos anfibólios, guardando esses minerais a mesma paragênese de rochas anfibolíticas.

Petrografia O corpo anfibolítico do Jaraguá é heterogêneo quanto à composição mineralógica. Anfibólio e feldspato constituem, juntos, mais de $80 \%$ do volume da rocha para a totalidade das amostras investigadas. Quartzo ocorre subordinadamente, enquanto que opacos e titanita constituem seus principais acessórios. Dentre os produtos de alteração, destaca-se o epídoto, que, por vezes, chega a alcançar grandes concentrações. Texturalmente, essas rochas exibem variações marcantes a ponto de ser possível distinguirem-se, dentro do corpo anfibolítico, duas zonas petrográficas distintas.

Zona A. Ocupando as porções centro-oeste do corpo, é definida pela existência de rochas com xistosidade bem desenvolvida e granulação fina.

Conquanto a amostragem sistemática do corpo anfibolítico seja de difícil execução, tendo-se em vista principalmente a profunda alteração intempérica a que estão sujeitas as rochas aflorando na região, crê-se que esse caráter textural seja o dominante.

Zona B. Correspondendo às partes sul-sudeste do corpo, é caracterizada pela presença de rochas com estrutura xistosa pouco pronunciada, textura marcadamente granoblástica e granulação grossa. Esses anfibolitos são encontrados junto à região de contato com o maciço granítico da Cantareira.

A composição modal média para as Zonas A e B, calculada a partir dos valores fornecidos em Gomes (1971), é dada na Tab. I.

No seu todo, esses dados permitem observar que, a despeito da distribuição errática de alguns minerais junto aos diversos exemplares do grupo, como observado em Gomes (1971), existem variações mineralógicas expressivas nas rochas das duas zonas. Estas consistem principalmente da maior concentração em hornblenda e epídoto e menor em plagioclásio das amostras da Zona A. Uma melhor visualização dessas diferenças é obtida junto à Fig. 2. 
Tabela I - Composição modal média de anfibolitos

\begin{tabular}{lrr}
\hline & Zona A & Zona B \\
\hline \hline Hornblenda & 74,5 & 66,9 \\
Plagioclásio & 12,2 & 23,4 \\
Quartzo & 2,6 & 3,7 \\
Epídoto & 6,8 & 1,8 \\
Titanita & 1,3 & 2,3 \\
Opacos & 2,6 & 1,8 \\
Apatita & - & 0,1 \\
\hline
\end{tabular}

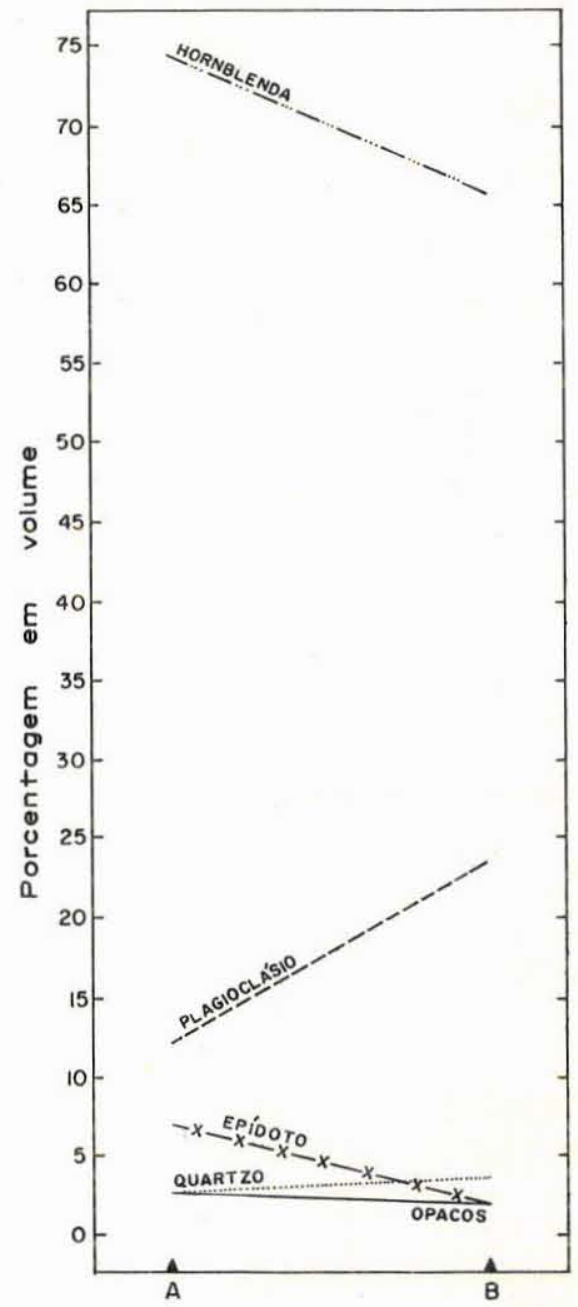

Figura 2 - Variações mineralógicas exibidas pelos anfibolitos das Zonas A e B

À exceção dos anfibólios intensamente zonados, que deverão ser objeto de apreciação isolada, os demais, a julgar por seus dados ópticos, pertencem ao grupo das hornblendas comuns. Esses minerais assumem, nas rochas anfibolíticas, formas distintas, tendo sido reconhecidos dois hábitos dominantes: granular e fibroso. A forma granular, com os cristais apresentando, em geral, dimensões milimétricas, é mais característica das amostras da Zona B, enquanto que a fibrosa, de tamanho submilimétrico, associa-se mais freqüentemente aos anfibolitos de granulação fina, comuns à Zona A. Usualmente, os cristais ostentando forma granular constituem porfiroblastos, que se mostram sempre crivados de pequenas inclusões, quartzo e, em menor quantidade, feldspatos, originando, assim, estruturas poiquiloblásticas.

Ao microscópio, os anfibólios exibem coloração predominante verde para $Z$, ocorrendo subordinadamente tonalidades mais claras, ou mesmo verde-azuladas; estas últimas específicas de minerais ligados a algumas amostras de rochas da região de contato com o maciço granítico.

Dados ópticos obtidos em programas anteriores (Gomes, 1962; Gomes et al., 1964) permitiram o estabelecimento de variações na composição desses minerais, com os valores do índice de refração $n_{z}$ aumentando e os do $2 V$ diminuindo junto às amostras da Zona B. 
Usando como parâmetro o número de Niggli $m g$ das hornblendas, extraído a partir de análises químicas e modais dos anfibolitos, esses últimos autores encontraram relações significativas entre aquele índice e as propriedades ópticas mencionadas, possibilitando a conclusão de que, nas proximidades do corpo intrusivo, os anfibólios dessas rochas apresentam-se em geral mais enriquecidos em ferro e, conseqüentemente, mais empobrecidos em magnésio.

Composição química A coleta de informações químicas processou-se em duas etapas distintas, com participação na primeira fase dos pesquisadores M. C. Oosterwyck-Gastuche e C. V. Dutra. Esse programa, inicialmente mais despretensioso, viu-se, porém, ampliado face à oportunidade surgida para a realização de um trabalho maior envolvendo o quimismo não só dos anfibólios, como também dos demais minerais dos anfibolitos. Assim, dez amostras de anfibólios foram reanalisadas para seus elementos principais, usando-se a técnica da microssonda. Eventuais diferenças nos resultados obtidos por meio da microssonda e fluorescência de raios $\mathrm{X}$ decorrem do fato de que as amostras examinadas não eram as mesmas, a despeito de provenientes do mesmo afloramento, da presença de impurezas minerais nos concentrados de anfibólio, da menor precisão dos dados analíticos obtidos com fluorescência de raios $\mathrm{X}$ face à utilização de padrões menos adequados, etc.

Tabela II - Composição química das hornblendas da Zona A

\begin{tabular}{lrrrrr}
\hline & JA-7 & JA-28 & JA-31 & JA-33 & JA-39 \\
\hline \hline $\mathrm{SiO}_{2}$ & 43,35 & 45,52 & 46,04 & 43,17 & 44,32 \\
$\mathrm{TiO}_{2}$ & 0,97 & 0,69 & 0,83 & 0,80 & 0,85 \\
$\mathrm{Al}_{2} \mathrm{O}_{3}$ & 8,68 & 7,01 & 8,94 & 9,41 & 9,05 \\
$\mathrm{Fe}_{2} \mathrm{O}_{3}$ & 10,05 & 6,62 & 4,54 & 8,83 & 5,92 \\
$\mathrm{FeO}$ & 11,76 & 10,80 & 10,62 & 12,05 & 12,91 \\
$\mathrm{MnO}$ & 0,12 & 0,12 & 0,10 & 0,13 & 0,13 \\
$\mathrm{MgO}$ & 9,43 & 11,90 & 12,75 & 7,90 & 11,95 \\
$\mathrm{CaO}$ & 11,93 & 13,19 & 11,44 & 13,82 & 10,84 \\
$\mathrm{Na}_{2} \mathrm{O}$ & 1,22 & 0,84 & 1,32 & 1,00 & 1,30 \\
$\mathrm{~K}_{2} \mathrm{O}$ & 0,42 & 0,35 & 0,27 & 0,25 & 0,21 \\
$\mathrm{H}_{2} \mathrm{O}^{+}$ & 2,43 & 2,51 & 2,52 & 2,49 & 2,27 \\
$\mathrm{H}_{2} \mathrm{O}^{-}$ & 0,12 & 0,45 & 0,35 & 0,35 & 0,51 \\
\multicolumn{1}{c}{ TOTAL } & 100,48 & 100,00 & 99,72 & 100,20 & 100,26
\end{tabular}

Elementos-traços (ppm)

\begin{tabular}{lrrrrr}
$\mathrm{Ga}$ & 20 & 16 & 19 & 18 & 18 \\
$\mathrm{Cr}$ & 380 & 200 & 124 & 150 & 400 \\
$\mathrm{~V}$ & 410 & 300 & 280 & 410 & 360 \\
$\mathrm{Ni}$ & 152 & 140 & 106 & 112 & 180 \\
$\mathrm{Co}$ & 70 & 64 & 56 & 56 & 60 \\
$\mathrm{Cu}$ & 4 & 36 & 28 & 8 & 17 \\
$\mathrm{Sc}$ & 68 & 50 & 58 & 64 & 68 \\
$\mathrm{Zr}$ & 50 & 500 & 50 & 40 & 52 \\
$\mathrm{Y}$ & 56 & $\mathrm{nd}$ & 42 & 46 & 50 \\
$\mathrm{Sr}$ & 36 & 42 & 46 & 80 & 44 \\
$\mathrm{Ba}$ & 50 & 50 & 50 & 60 & 60 \\
\hline
\end{tabular}

Analistas: Elementos principais - M. C. O. Gastuche Elementos-traços - C. V. Dutra 
Tabela III - Fórmula química (número de íons na base de 24 átomos de oxigênio) das hornblendas da Zona A

\begin{tabular}{lccccc}
\hline & JA-7 & JA-28 & JA-31 & JA-33 & JA-39 \\
\hline \hline $\mathrm{Si}$ & 6,455 & 6,732 & 6,726 & 6,464 & 6,570 \\
$\mathrm{Al}^{\mathrm{IV}}$ & 1,520 & 1,224 & 1,274 & 1,536 & 1,430 \\
$\mathrm{Al}^{\mathrm{VI}}$ & - & - & 0,270 & 0,118 & 0,152 \\
$\mathrm{Ti}^{3+}$ & 0,107 & 0,080 & 0,088 & 0,090 & 0,098 \\
$\mathrm{Fe}^{3+}$ & 1,126 & 0,728 & 0,490 & 0,988 & 0,658 \\
$\mathrm{Mn}^{2+}$ & 0,018 & 0,018 & 0,009 & 0,018 & 0,018 \\
$\mathrm{Fe}^{2+}$ & 1,457 & 1,330 & 1,289 & 1,501 & 1,591 \\
$\mathrm{Mg}$ & 2,110 & 2,634 & 2,798 & 1,771 & 2,658 \\
$\mathrm{Ca}$ & 1,904 & 2,084 & 1,789 & 2,220 & 1,716 \\
$\mathrm{Na}$ & 0,358 & 0,230 & 0,368 & 0,288 & 0,374 \\
$\mathrm{~K}$ & 0,072 & 0,070 & 0,052 & 0,054 & 0,036 \\
$\mathrm{OH}$ & 2,414 & 2,466 & 2,456 & 2,482 & 2,276 \\
$\mathrm{Y}$ & 4,82 & 4,79 & 4,94 & 4,49 & 5,17 \\
$\mathrm{X}$ & 2,33 & 2,38 & 2,21 & 2,56 & 2,13 \\
\hline
\end{tabular}

Tabela IV - Composição química das hornblendas da Zona B

\begin{tabular}{lrrrrr}
\hline & JA-11 & JA-15 & JA-16 & JA-17 & JA-18 \\
\hline \hline $\mathrm{SiO}_{2}$ & 43,33 & 41,70 & 38,99 & 43,14 & 46,67 \\
$\mathrm{TiO}_{2}$ & 0,69 & 0,82 & 0,90 & 1,61 & 0,81 \\
$\mathrm{Al}_{2} \mathrm{O}_{3}$ & 9,43 & 9,39 & 10,79 & 8,68 & 8,94 \\
$\mathrm{Fe}_{2} \mathrm{O}_{3}$ & 9,11 & 10,11 & 9,12 & 9,46 & 4,88 \\
$\mathrm{FeO}$ & 12,32 & 12,84 & 17,99 & 11,90 & 12,97 \\
$\mathrm{MnO}$ & 0,14 & 0,10 & 0,15 & 0,15 & 0,07 \\
$\mathrm{MgO}$ & 8,40 & 7,80 & 4,35 & 8,40 & 10,12 \\
$\mathrm{CaO}$ & 12,60 & 12,91 & 12,46 & 13,08 & 11,18 \\
$\mathrm{Na}_{2} \mathrm{O}$ & 1,04 & 1,10 & 1,02 & 0,83 & 1,10 \\
$\mathrm{~K}_{2} \mathrm{O}$ & 0,43 & 0,43 & 0,75 & 0,33 & 0,25 \\
$\mathrm{H}_{2} \mathrm{O}^{+}$ & 2,41 & 2,31 & 2,62 & 2,32 & 2,58 \\
$\mathrm{H}_{2} \mathrm{O}^{-}$ & 0,28 & 0,44 & 0,26 & 0,28 & 0,50 \\
\multicolumn{1}{c}{ TOTAL } & 100,18 & 99,95 & 99,40 & 100,18 & 100,07
\end{tabular}

\begin{tabular}{lrrrrr}
$\mathrm{Ga}$ & 18 & 18 & 28 & 20 & 22 \\
$\mathrm{Cr}$ & 46 & 74 & 62 & 92 & 36 \\
$\mathrm{~V}$ & 430 & 420 & 500 & 520 & 400 \\
$\mathrm{Ni}$ & 116 & 120 & 48 & 76 & 102 \\
$\mathrm{Co}$ & 74 & 72 & 74 & 68 & 54 \\
$\mathrm{Cu}$ & 124 & 54 & 30 & 42 & 80 \\
$\mathrm{Sc}$ & 68 & 70 & 60 & 58 & 62 \\
$\mathrm{Zr}$ & 68 & 40 & $\mathrm{nd}$ & 100 & nd \\
$\mathrm{Y}$ & 46 & 50 & 68 & 60 & 110 \\
$\mathrm{Sr}$ & 46 & 64 & 46 & 62 & 40 \\
$\mathrm{Ba}$ & 70 & 80 & 80 & 60 & 80 \\
\hline
\end{tabular}


Para uma melhor apreciação, esses resultados são apresentados em tabelas independentes. Dessa forma, a composição dos elementos principais, obtida por fluorescência de raios X e espectrografia, de dez anfibólios das Zonas A e B é dada nas Tabs. II e IV, com suas fórmulas químicas, calculadas na base de $24(\mathrm{O}, \mathrm{OH}, \mathrm{F}, \mathrm{Cl})$, integrando as Tabs. III e V. A composição média para as duas zonas consta da. Tab. VI. O trabalho executado com a microssonda forneceu os valores constantes das Tabs. VII e IX. As fórmulas químicas desses minerais, expressas na base de 23 átomos de oxigênio, são dadas nas Tabs. VIII e X, enquanto que a composição média para as duas zonas encontra-se na Tab. XI.

Tabela V - Fórmula química (número de íons na base de 24 átomos de oxigênio) das hornblendas da Zona B

\begin{tabular}{lccccc} 
& JA-11 & JA-15 & JA-16 & JA-17 & JA-18 \\
\hline \hline $\mathrm{Si}$ & 6,483 & 6,345 & 6,084 & 6,471 & 6,846 \\
$\mathrm{Al}^{\mathrm{IV}}$ & 1,517 & 1,655 & 1,916 & 1,529 & 1,154 \\
$\mathrm{Al}^{\mathrm{VI}}$ & 0,135 & 0,025 & 0,068 & 0,001 & 0,394 \\
$\mathrm{Ti}^{3+}$ & 0,081 & 0,091 & 0,103 & 0,180 & 0,088 \\
$\mathrm{Fe}^{3+}$ & 1,024 & 1,150 & 1,066 & 1,062 & 0,528 \\
$\mathrm{Mn}^{2+}$ & 0,018 & 0,009 & 0,019 & 0,018 & 0,009 \\
$\mathrm{Fe}^{2+}$ & 1,535 & 1,625 & 2,340 & 1,485 & 1,584 \\
$\mathrm{Mg}$ & 1,886 & 1,780 & 1,020 & 1,890 & 2,226 \\
$\mathrm{Ca}$ & 2,020 & 2,100 & 2,078 & 2,097 & 1,760 \\
$\mathrm{Na}$ & 0,306 & 0,328 & 0,300 & 0,234 & 0,316 \\
$\mathrm{~K}$ & 0,072 & 0,072 & 0,150 & 0,054 & 0,052 \\
$\mathrm{OH}$ & 2,406 & 2,338 & 2,714 & 2,322 & 2,516 \\
$\mathrm{Y}$ & 4,68 & 4,68 & 4,62 & & \\
& 2,40 & 2,50 & 2,53 & 4,64 & 4,82 \\
$\mathrm{X}$ & & & & 2,38 & 2,13 \\
\hline
\end{tabular}

Discussão dos resultados A primeira conclusão a ser extraída dos resultados apresentados reside na caracterização imediata desses minerais, em consonância com Leake (1968) e outros, como anfibólios calcíferos, tendo-se em vista o fato de apresentarem valores acima do limite inferior de 1,5 átomos de Ca por fórmula unitária estabelecido para o grupo. $\mathrm{Na}$ totalidade dos dados determinados com microssonda, é respeitado também o limite superior de 2,0 átomos de Ca fixado por Hallimond (1943), enquanto que o mesmo não ocorre com alguns dos obtidos por fluorescência de raios $\mathrm{X}$. Contudo este último aspecto não se reveste de grande importância devido ao fato de o excesso ser relativamente pequeno e dos resultados conseguidos com a primeira técnica serem, no presente caso, mais precisos.

Quando projetados no gráfico da Fig. 3, reunindo $\mathrm{Al}^{\mathrm{IV}}$ e $(\mathrm{Na}+\mathrm{K})$, conforme Deer et al. (1963, vol. 2: 272), os dados químicos permitem situar os anfibólios analisados preferencialmente nas vizinhanças do campo da hornblenda, com as variações restritas ao funil definido pelos membros finais pargasita e tremolita. Em virtude do seu maior número, julgou-se mais conveniente para a caracterização desses anfibólios a utilização dos resultados constantes apenas das Tabs. VII e IX. Verifica-se, assim, em concordância com observações de outros autores, a inexistência de cristais com composição próxima ao membro tschermakita. Se adotada a nova classificação de anfibólios calcíferos, proposta por Leake 
Tabela VI - Composição química média de hornblendas

\begin{tabular}{|c|c|c|}
\hline & Zona $\mathrm{A}^{*}$ & Zona $\mathrm{B}^{* *}$ \\
\hline $\mathrm{SiO}_{2}$ & 44,5 & 42,8 \\
\hline $\mathrm{TiO}_{2}^{2}$ & 0,83 & 0,97 \\
\hline $\mathrm{Al}_{2} \mathrm{O}_{3}$ & 8,62 & 9,45 \\
\hline $\mathrm{Fe}_{2} \mathrm{O}_{3}$ & 7,19 & 8,54 \\
\hline $\mathrm{FeO}^{3}$ & 11,6 & 13,6 \\
\hline $\mathrm{MnO}$ & 0,12 & 0,12 \\
\hline $\mathrm{MgO}$ & 10,8 & 7,81 \\
\hline $\mathrm{CaO}$ & 12,2 & 12,4 \\
\hline $\mathrm{Na}_{2} \mathrm{O}$ & 1,14 & 1,02 \\
\hline $\mathrm{K}_{2} \mathrm{O}$ & 0,30 & 0,44 \\
\hline $\mathrm{H}_{2} \mathrm{O}^{+}$ & 2,44 & 2,45 \\
\hline $\mathrm{H}_{2} \mathrm{O}^{-}$ & 0,36 & 0,35 \\
\hline TOTAL & 100,10 & 99,95 \\
\hline
\end{tabular}

Elementos-traços (ppm)

\begin{tabular}{lrr}
$\mathrm{Ga}$ & 18 & 21 \\
$\mathrm{Cr}$ & 251 & 62 \\
$\mathrm{~V}$ & 352 & 454 \\
$\mathrm{Ni}$ & 138 & 92 \\
$\mathrm{Co}$ & 61 & 68 \\
$\mathrm{Cu}$ & 19 & 66 \\
$\mathrm{Sc}$ & 62 & 64 \\
$\mathrm{Zr}$ & 138 & 42 \\
$\mathrm{Y}$ & 39 & 67 \\
$\mathrm{Sr}$ & 56 & 52 \\
$\mathrm{Ba}$ & 54 & 71 \\
\hline
\end{tabular}

* Média obtida a partir de cinco amostras constantes da Tab. II

**Média obtida a partir de cinco amostras constantes da Tab. IV

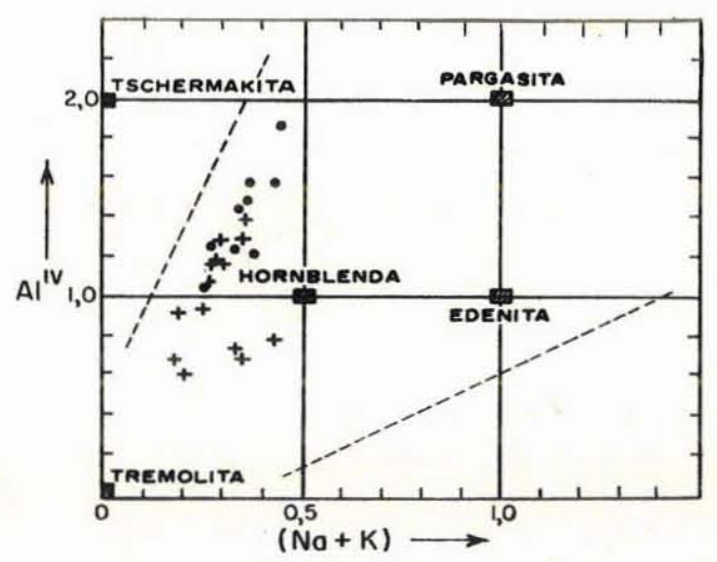

Figura 3 - Projeção dos anfibólios analisados (dados por microssonda) no diagrama de nomenclatura de Deer et al. (1963, vol. 2). Zoná A (+) e Zona B (.)

(1968, p. 7), observa-se que a maior parte desses minerais parece corresponder às variedades magnésio-hornblenda e ferro-hornblenda, que têm seus campos de variação fixados pelos valores limites; número de Niggli $m g$, respectivamente, $=0,50-1,00$ e 0,00-0,50; $\mathrm{Si}=$ $=6,50-7,25$ e $(\mathrm{Ca}+\mathrm{Na}+\mathrm{K})=2,00-2,50$, com apenas algumas amostras da Zona $\mathrm{A}$ apresentando pequenas oscilações de composição para hornblenda actinolítica e da Zona B 
Tabela VII - Composição química parcial das hornblendas da Zona A

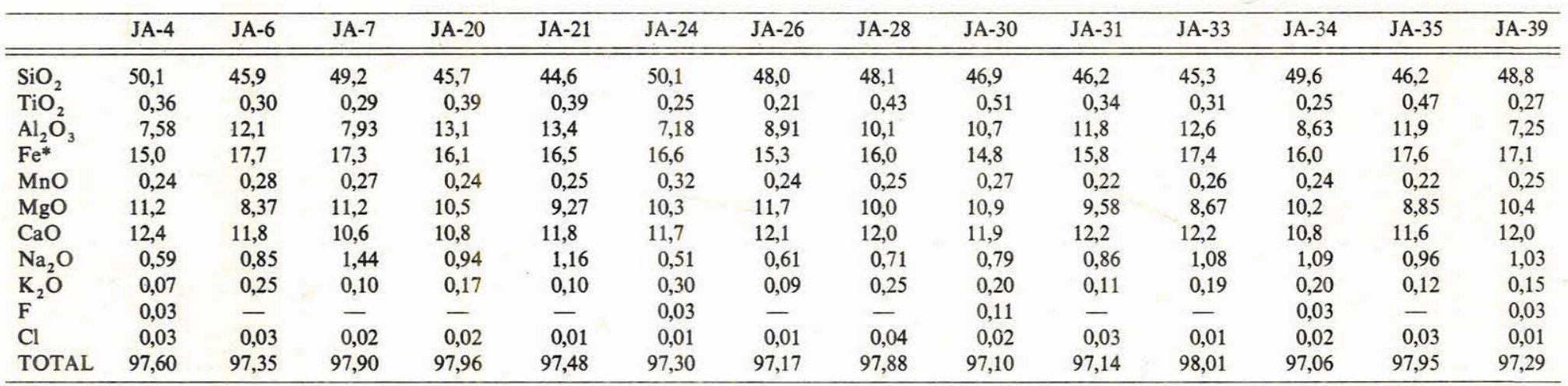

* $\mathrm{Fe}$ calculado na forma de $\mathrm{FeO}$

Analista: C. B. Gomes

Tabela VIII - Fórmula química (número de íons na base de 23 átomos de oxigênio) das hornblendas da Zona A

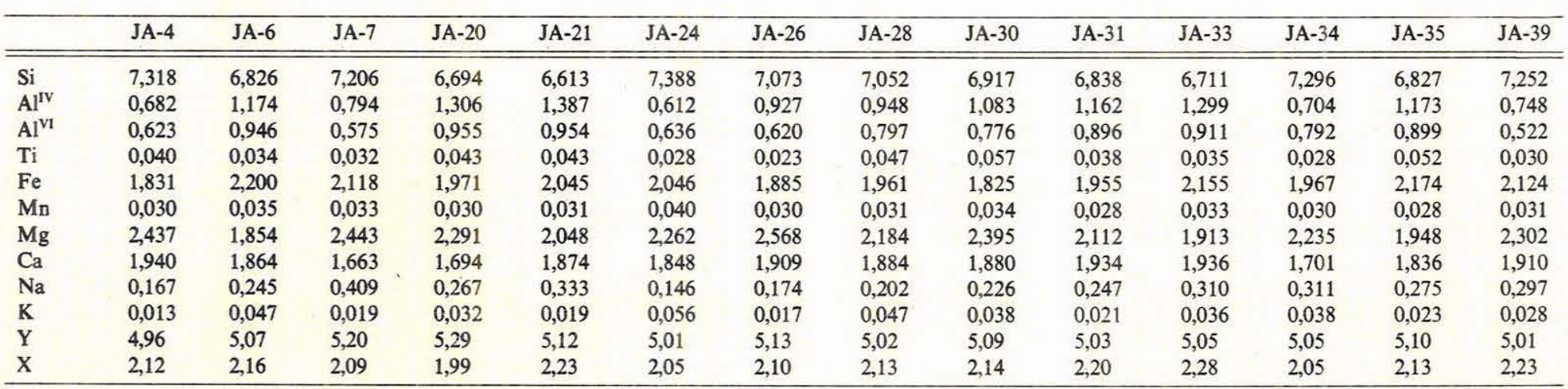


Tabela IX - Composição química parcial das hornblendas da Zona B

\begin{tabular}{lccccccccc}
\hline & JA-9 & JA-11 & JA-12 & JA-13 & JA-14 & JA-15 & JA-16 & JA-17 & JA-19 \\
\hline \hline $\mathrm{SiO}_{2}$ & 45,1 & 43,8 & 46,4 & 42,2 & 42,1 & 43,0 & 40,4 & 45,5 & 44,7 \\
$\mathrm{TiO}_{2}$ & 0,50 & 0,40 & 0,46 & 0,54 & 0,48 & 0,44 & 0,45 & 0,35 & 0,53 \\
$\mathrm{Al}_{2} \mathrm{O}_{3}$ & 11,4 & 13,4 & 10,8 & 14,4 & 14,9 & 13,9 & 15,7 & 12,9 & 11,3 \\
$\mathrm{FeO}^{*}$ & 19,1 & 18,0 & 17,6 & 20,0 & 20,7 & 18,7 & 22,1 & 17,8 & 18,3 \\
$\mathrm{MnO}$ & 0,30 & 0,31 & 0,29 & 0,29 & 0,30 & 0,28 & 0,30 & 0,27 & 0,30 \\
$\mathrm{MgO}$ & 7,74 & 8,59 & 8,79 & 6,43 & 5,49 & 7,69 & 5,01 & 7,61 & 8,65 \\
$\mathrm{CaO}$ & 12,0 & 12,1 & 11,8 & 11,8 & 11,9 & 11,8 & 11,8 & 12,0 & 12,2 \\
$\mathrm{Na}_{2} \mathrm{O}$ & 0,96 & 0,96 & 0,81 & 0,94 & 1,08 & 0,96 & 1,08 & 0,89 & 0,82 \\
$\mathrm{~K}_{2} \mathrm{O}$ & 0,50 & 0,33 & 0,12 & 0,50 & 0,59 & 0,43 & 0,65 & 0,37 & 0,13 \\
$\mathrm{~F}$ & - & - & - & - & - & - & 0,05 & - & - \\
$\mathrm{Cl}$ & 0,04 & 0,05 & 0,04 & 0,11 & 0,11 & 0,05 & 0,18 & 0,02 & 0,04 \\
\multicolumn{1}{c}{ TOTAL } & 97,64 & 97,94 & 97,11 & 97,10 & 97,65 & 97,25 & 97,72 & 97,71 & 97,79 \\
\hline
\end{tabular}

* Fe calculado na forma de $\mathrm{FeO}$

Analista: C. B. Gomes

Tabela X - Fórmula química (número de íons na base de 23 átomos de oxigênio) das hornblendas da Zona B

\begin{tabular}{llllllllll}
\hline & JA-9 & JA-11 & JA-12 & JA-13 & JA-14 & JA-15 & JA-16 & JA-17 & JA-19 \\
\hline \hline $\mathrm{Si}$ & 6,782 & 6,538 & 6,924 & 6,425 & 6,406 & 6,490 & 6,215 & 6,764 & 6,739 \\
$\mathrm{Al}^{\mathrm{IV}}$ & 1,218 & 1,462 & 1,076 & 1,575 & 1,594 & 1,510 & 1,875 & 1,236 & 1,261 \\
$\mathrm{Al}^{\mathrm{VI}}$ & 0,802 & 0,895 & 0,823 & 1,008 & 1,077 & 0,962 & 0,971 & 1,024 & 0,747 \\
$\mathrm{Ti}$ & 0,057 & 0,045 & 0,052 & 0,062 & 0,055 & 0,050 & 0,052 & 0,039 & 0,060 \\
$\mathrm{Fe}$ & 2,401 & 2,246 & 2,195 & 2,545 & 2,633 & 2,359 & 2,842 & 2,212 & 2,306 \\
$\mathrm{Mn}$ & 0,038 & 0,039 & 0,037 & 0,037 & 0,039 & 0,036 & 0,039 & 0,034 & 0,038 \\
$\mathrm{Mg}$ & 1,734 & 1,910 & 1,954 & 1,458 & 1,244 & 1,729 & 1,148 & 1,685 & 1,943 \\
$\mathrm{Ca}$ & 1,933 & 1,934 & 1,886 & 1,924 & 1,939 & 1,907 & 1,944 & 1,910 & 1,970 \\
$\mathrm{Ia}$ & 0,280 & 0,278 & 0,234 & 0,277 & 0,318 & 0,281 & 0,322 & 0,256 & 0,240 \\
$\mathrm{~K}$ & 0,096 & 0,063 & 0,023 & 0,097 & 0,114 & 0,083 & 0,128 & 0,070 & 0,025 \\
$\mathrm{Y}$ & 5,03 & 5,13 & 5,06 & 5,11 & 5,05 & 5,14 & 5,05 & 4,99 & 5,09 \\
$\mathrm{X}$ & 2,31 & 2,27 & 2,14 & 2,30 & 2,37 & 2,27 & 2,39 & 2,24 & 2,23 \\
\hline
\end{tabular}

para hornblenda tschermakítica e ferro-tschermakita. A projeção desses valores é vista na Fig. 4.

Os números obtidos para $\mathrm{Al}^{\mathrm{IV}}$, exprimindo o grau de substituição estrutural de $\mathrm{Si}$ por $\mathrm{Al}$, são inferiores ao limite de dois átomos por fórmula unitária estabelecido para o grupo das hornblendas, com a amostra JA-16 exibindo, nas duas séries de análises, os valores mais altos, respectivamente, 1,916 e 1,875 (Tabs. V e X).

A ocupação da posição estrutural X é feita principalmente por cálcio e sódio, com o potássio assumindo papel secundário. À exceção de duas amostras JA-16 e JA-33 (Tabs. III e V), todas as demais possuem $\Sigma \mathrm{X}$ igual ou inferior a 2,50. Todavia o excesso mencionado é destituído de maior significado, tendo-se em vista que essas amostras, quando examinadas por microssonda, apresentaram valores dentro do intervalo 2,00-2,50. Isso, não obstante terem se constituído nas espécies $\operatorname{com} \Sigma \mathrm{X}$ mais altos, junto às demais amostras de cada zona. 


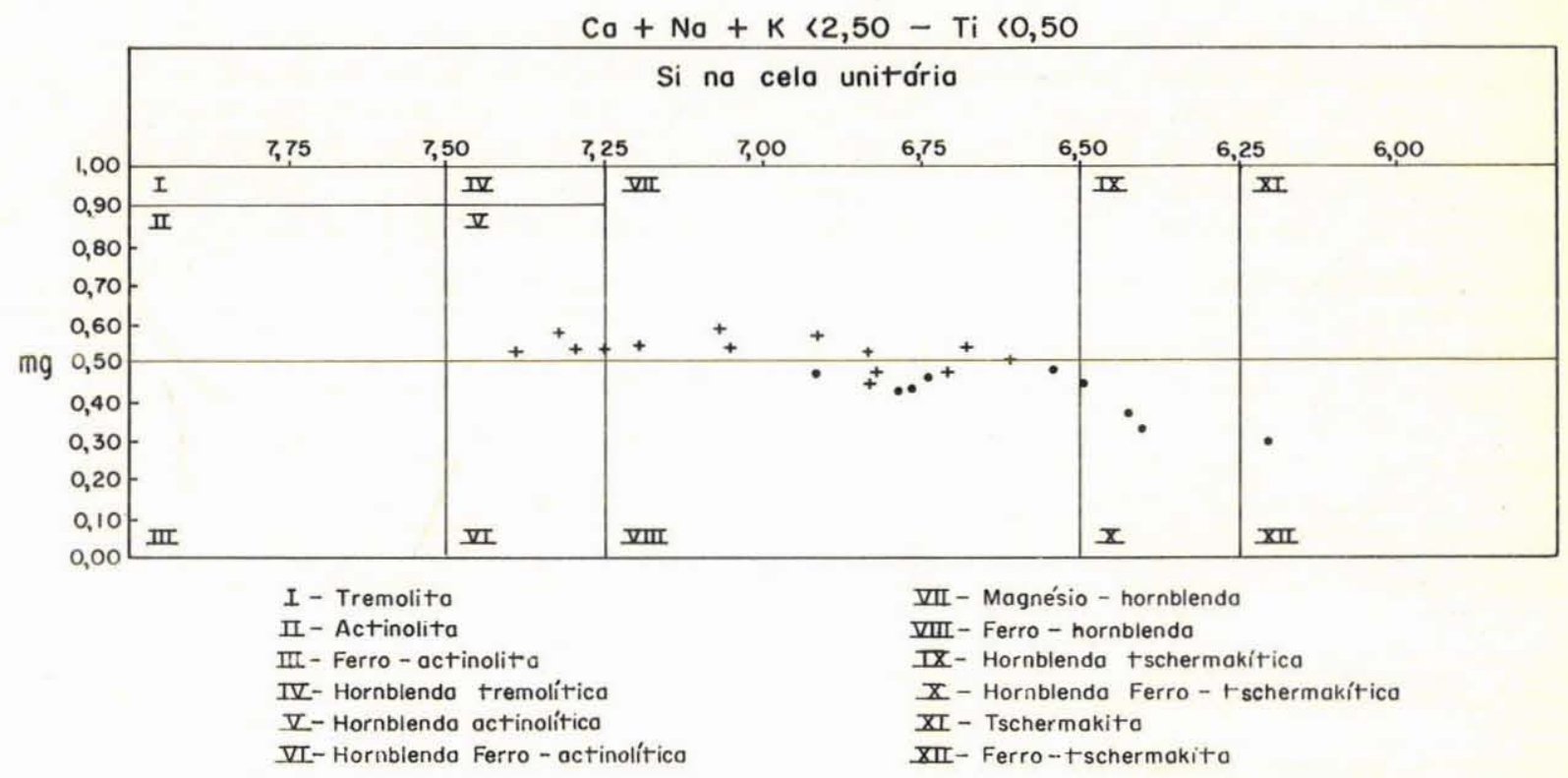

Figura 4 - Projeção dos anfibólios analisados (dados por microssonda) no diagrama de nomenclatura de Leake (1968). Zona A (+) e Zona B (.)

A Fig. 3 parece indicativa da existência de variação no conteúdo de $\mathrm{Al}^{\mathrm{IV}}$ nas amostras das duas zonas, com as da Zona A mostrando-se em geral menos enriquecidas em alumínio de coordenação tetraédrica. Essa observação, a despeito do pequeno número de pontos e da sua parcial superposição, é reforçada pelo diagrama da Fig. 5, relativo aos teores $\mathrm{Al}^{\mathrm{IV}}$ e $\mathrm{Al}^{\mathrm{VI}}$, com dados extraídos das Tabs. VIII e X.

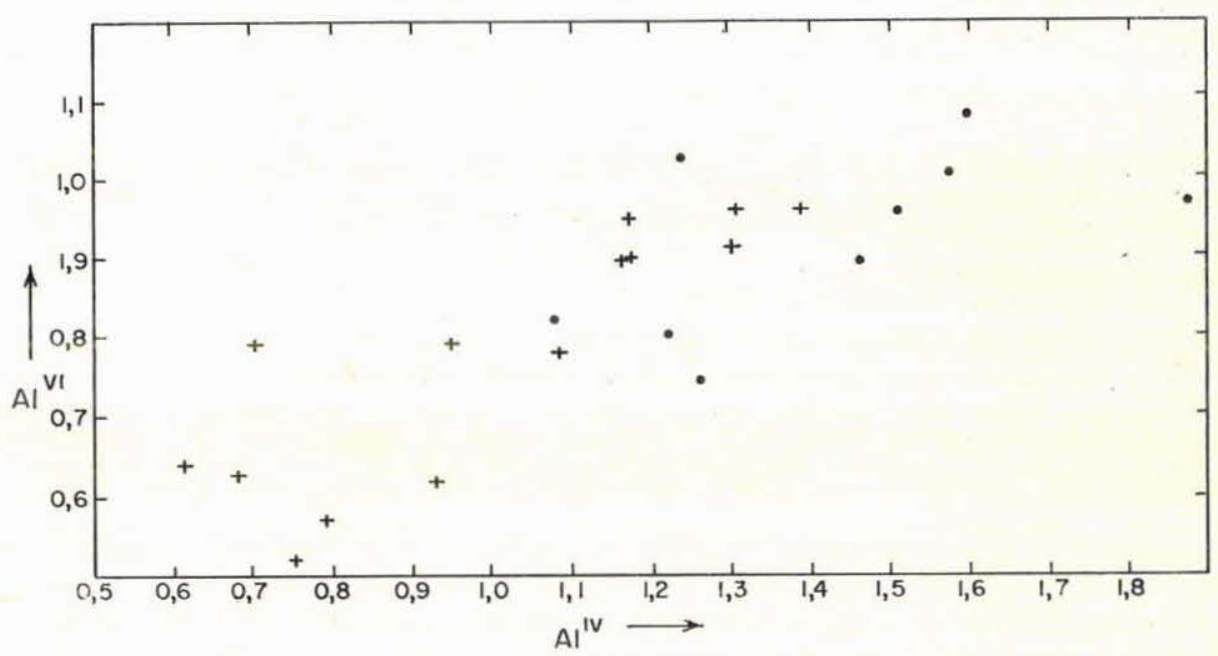

Figura 5-Relação entre alumínio de coordenação tetraédrica e alumínio de coordenação octaédrica para os anfibólios do Jaraguá. Zona A (+) e Zona B (.) 
A Fig. 6, reunindo Ca em X e $\Sigma$ Y, representa uma tentativa de correlação entre a quantidade de cálcio ocupando a posição estrutural $\mathrm{X}$ e o excesso de cátions do grupo $\mathrm{Y}$, uma vez assumido que, segundo Hallimond (1943), a maioria das hornblendas contém 1,8 $\pm 0,1$ átomos de Ca por fórmula unitária. Aparentemente, há um ligeiro esboço dessa correlação nas variedades da Zona A, entretanto o mesmo não é válido para as da Zona $\mathrm{B}$, portadoras, na maioria das vezes, de concentrações acima dos limites para as duas posições estruturais.

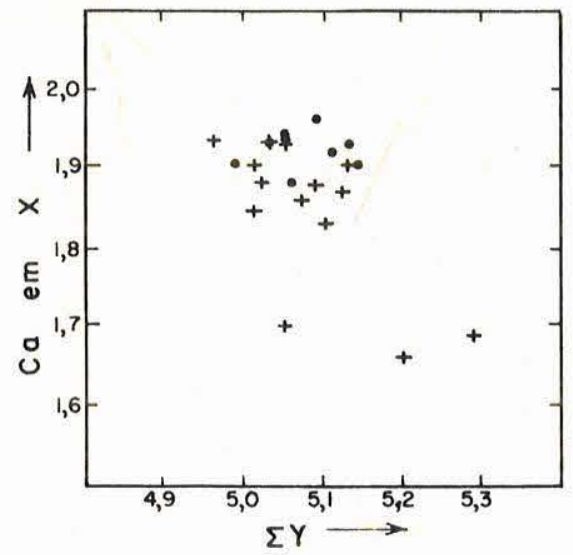

Figura 6 - Gráfico reunindo Ca presente em X e a soma dos cátions do grupo Y. Zona A (+) e Zona B (.)

Conquanto os dados coligidos nos programas analíticos com a microssonda e fluorescência de raios $\mathrm{X}$ apontem algumas diferenças, ainda que se tratando de amostras catalogadas sob o mesmo número, é particularmente importante verificar que, no seu conjunto, as variações encontradas para as duas zonas guardam uma correspondência quase que completa, como se depreende das Talss. VI e XI. Assim, vê-se nitidamente que essas mudanças expressam, segundo o esquema de classificação de Leake (1968, p. 8), uma tendência no sentido da formação de hornblendas actinolíticas junto às amostras da Zona A. Quimicamente, essas modificações estão traduzidas no aumento das concentrações de sílica e magnésio e da diminuição do teor de alumínio e ferro. Tais conclusões, indicativas de que esses últimos anfibólios mostram-se mais ricos em magnésio e mais pobres em ferro, são similares às alcançadas por Gomes (1962) e Gomes et al. (1964). Variação subordinada, considerando-se a baixa concentração desse elemento, porém de grande implicação genética, é dada também pelo decréscimo do conteúdo de titânio.

Uma melhor visualização dessas modificações é fornecida na Fig. 7, com valores extraídos das tabelas referidas anteriormente.

A composição espectrográfica desses anfibólios sofreu, da mesma maneira, mudanças, refletidas na maior concentração em $\mathrm{V}, \mathrm{Ba}, \mathrm{Y}$ e $\mathrm{Cu}$ e, menor, em $\mathrm{Cr}$, $\mathrm{Ni}$ e $\mathrm{Zr}$ nas amostras da Zona B, como indicado na Tab. VI e visto na Fig. 8. Ca, GO, Sc e Sr mantiveram-se mais ou menos constantes.

Zoneamento Uma das feições mais expressivas desses anfibólios consiste na presença das estruturas zonadas, com as partes centrais dos cristais apresentando invariavelmente cores mais claras que as das bordas. Uma visão desse aspecto encontra-se em Gomes (1962, p. 74). Em geral, nota-se maior incidência do fenômeno nas amostras da Zona A. A fim de se ter uma idéia quanto às eventuais mudanças químicas ocorridas nesses cristais, como sugerido por suas variações ópticas, foi levado a efeito com o auxílio da microssonda um 

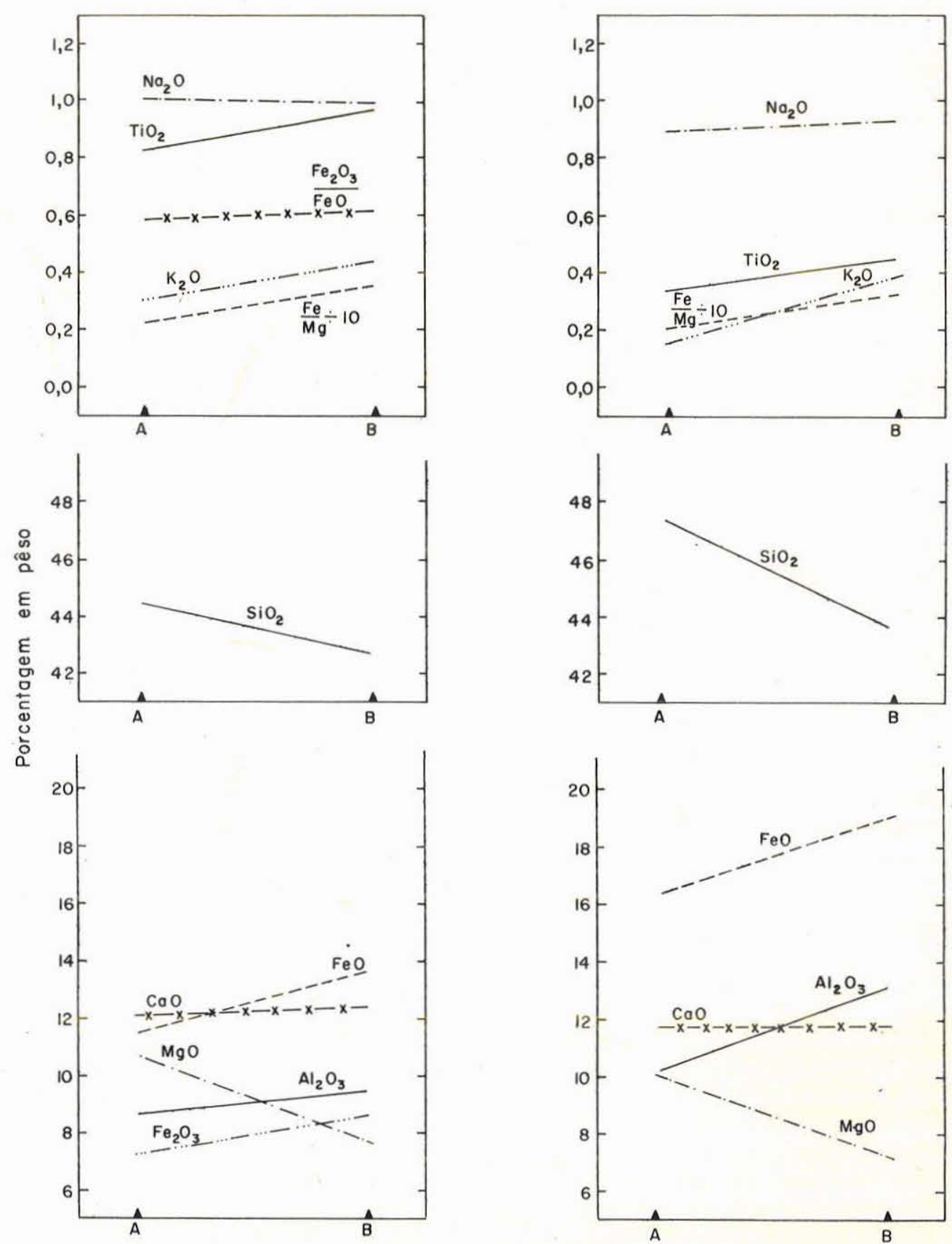

Figura 7 - Variações na composição química, elementos principais, dos anfibólios das Zonas A e B. À esquerda, curvas construídas a partir de dados obtidos por fluorescência de raios X e, à direita, por microssonda

programa quantitativo permitindo o "traçado" de transversais, com os pontos de análise igualmente distanciados de $3 \mu$. Como o zoneamento tem caráter assimétrico, à borda I do cristal examinado (amostra JA-28) corresponderam doze pontos, enquanto que, à borda 
Tabela XI - Composição química média de hornblendas

\begin{tabular}{|c|c|c|}
\hline & Zona $\mathrm{A}^{*}$ & Zona B** \\
\hline $\mathrm{SiO}_{2}$ & 47,5 & 43,7 \\
\hline $\mathrm{TiO}_{2}^{2}$ & 0,34 & 0,46 \\
\hline $\mathrm{Al}_{2} \mathrm{O}_{3}$ & 10,2 & 13,2 \\
\hline $\mathrm{FeO}^{* * *}$ & 16,4 & 19,1 \\
\hline $\mathrm{MnO}$ & 0,25 & 0,29 \\
\hline $\mathrm{MgO}$ & 10,1 & 7,33 \\
\hline $\mathrm{CaO}$ & 11,7 & 11,9 \\
\hline $\mathrm{Na}_{2} \mathrm{O}$ & 0,90 & 0,94 \\
\hline $\mathrm{K}_{2} \mathrm{O}$ & 0,16 & 0,40 \\
\hline $\mathrm{F}^{2}$ & 0,02 & 0,01 \\
\hline $\mathrm{Cl}$ & 0,03 & 0,07 \\
\hline TOTAL & 97,60 & 97,40 \\
\hline
\end{tabular}

* Média obtida a partir de catorze amostras constantes da Tab. VII

** Média obtida a partir de nove amostras constantes da Tab. IX

*** $\mathrm{Fe}$ calculado na forma de $\mathrm{FeO}$

II, apenas cinco. Já o núcleo fez-se melhor representar com aproximadamente vinte e cinco pontos. A delimitação dessas zonas viu-se facilitada em virtude das diferenças de cor apontadas acima. Os dados coligidos constam da Tab. XII, sendo também fornecidos os valores parciais para as duas bordas.

A apreciação desses resultados possibilita a conclusão imediata de que o núcleo dos cristais zonados contém mais sílica e magnésio e menos alumínio e ferro que a periferia. O teor de titânio aumenta no sentido das bordas, o inverso ocorrendo com os álcalis. Em termos de composição mineral, poder-se-ia dizer que as partes centrais desses cristais correspondem a uma actinolita; enquanto que as bordas, a uma magnésio-hornblenda ou ferro-hornblenda, uma vez adotada a classificação de Leake (1968). Se confrontados com os valores contidos nas Tabs. VI e XI, nota-se uma aproximação maior entre a composição química do núcleo, a despeito de esta representar um caso extremo, com a composição média dos anfibólios da Zona A e das bordas com a composição média dos anfibólios da Zona B.

Metamorfismo Considerações gerais Evidências mineralógicas e texturais, com as primeiras traduzidas na presença de quartzo, sericita e biotita como constituintes mineralógicos principais, são indicativas de que as rochas metassedimentares da região do Jaraguá foram afetadas por metamorfismo dinamotermal compatível com a fácies dos xistos verdes. A ausência de clorita nesses metassedimentos constitui, segundo Coutinho (1955), feição conclusiva de que as condições metamórficas ali reinantes atingiram grau mais elevado em relação aos estádios iniciais, correspondendo, assim, à subfácies quartzo-albita-epídoto-biotita, uma vez adotada a antiga classificação fornecida em Turner e Verhoogen (1960).

Os anfibolitos também se formaram pela ação desse processo, sendo ainda visíveis em sua constituição os efeitos dinâmicos por ele causados. A sua associação paragenética, própria de fácies mais elevada que a dos metassedimentos regionais e condizente com a almandina anfibolito dos últimos autores, denuncia a existência de desequilíbrio metamórfico dentro do quadro mineralógico das rochas da região. Aparentemente, esse fato poderia estar ligado à natureza do material original dos anfibolitos, mostrando maior defi- 
Figura 8 - Variações na composição química, elementos-traços, dos anfibólios das Zonas A e B. Curvas construídas a partir de dados obtidos por espectrografia óptica

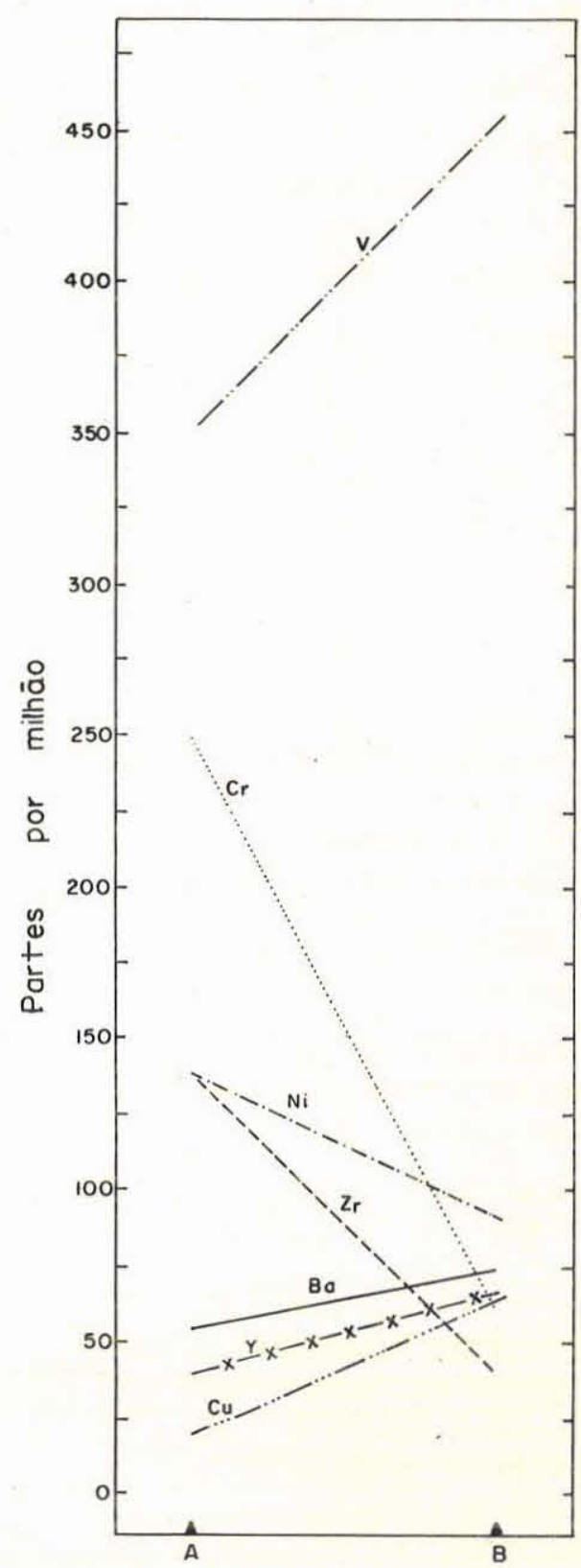

ciência em água relativamente às rochas encaixantes, uma vez assumida a sua derivação a partir de antigas intrusivas básicas.

Por outro lado, essas rochas, quando submetidas às condições metamórficas reinantes posteriormente à intrusão granítica da Cantareira, parecem ter-se comportado de maneira heterogênea, a julgar por suas variações mineralógicas e texturais. Como observado anteriormente, tornou-se possível o estabelecimento de duas zonas petrográficas distintas, com características mineralógicas e texturais próprias, dentro do corpo anfibolítico, que são encaradas como resposta dessas rochas às mudanças processadas no gradiente metamórfico. A elevação do gradiente poderia ser explicada em termos da existência de dois eventos 
Tabela XII - Composição química parcial da hornblenda zonada*

\begin{tabular}{|c|c|c|c|c|}
\hline \multicolumn{4}{|c|}{ Borda } & \multirow[t]{2}{*}{ Núcleo } \\
\hline & I & II & Média & \\
\hline $\mathrm{SiO}_{2}$ & 43,0 & 44,0 & 43,5 & 52,3 \\
\hline $\mathrm{TiO}_{2}$ & 0,32 & 0,36 & 0,34 & 0,08 \\
\hline $\mathrm{Al}_{2} \mathrm{O}_{3}$ & 13,0 & 10,7 & 11,9 & 3,18 \\
\hline $\mathrm{FeO}^{* *}$ & 17,2 & 16,9 & 17,1 & 13,2 \\
\hline $\mathrm{MnO}$ & 0,26 & 0,25 & 0,25 & 0,23 \\
\hline $\mathrm{MgO}$ & 8,17 & 9,22 & 8,69 & 13,8 \\
\hline $\mathrm{CaO}$ & 12,2 & 12,2 & 12,2 & 12,8 \\
\hline $\mathrm{Na}_{2} \mathrm{O}$ & 0,81 & 0,74 & 0,77 & 0,14 \\
\hline $\mathrm{K}_{2} \mathrm{O}$ & 0,35 & 0,37 & 0,36 & 0,11 \\
\hline TOTAL & 95,31 & 94,74 & 95,11 & 95,84 \\
\hline
\end{tabular}

*Amostra investigada JA-28; dados sujeitos à aplicação de fatores de correção **Fe calculado na forma de $\mathrm{FeO}$

metamórficos afetando a área. O primeiro, como já mencionado, estaria ligado ao processo de caráter mais regional, enquanto que o segundo, atuando em superposição ao anterior, encontra-se relacionado à intrusão granítica do maciço da Cantareira. Aparentemente, sua área de influência foi muito reduzida, uma vez que os anfibolitos da Zona A, distantes de algumas dezenas de metros da região de contato da intrusiva, parecem ter sido fracamente atingidos por ele, como testemunhado por sua mineralogia e textura. A interpretação de que as modificações acima resultam de variações na intensidade do metamorfismo encontra apoio em número apreciável de evidências de natureza diversa, que serão objeto de considerações mais pormenorizadas. Para efeito de análise comparativa, algumas evidências sugestivas de idêntico fenômeno, que foram reconhecidas em anfibólios de outras áreas, porém não confirmadas para os minerais do Jaraguá, serão igualmente objeto de citação.

Lividências químicas $\mathrm{O}$ exame dos dados da literatura ressalta prontamente que hornblenda, a variedade de anfibólio mais comum em anfibolitos, exibe mudanças químicas expressivas quando tais rochas vêem-se submetidas a condições variáveis de metamorfismo.

Coube a Wiseman (1934), em seu famoso trabalho sobre os epidioritos de Highlands, Escócia, a iniciativa pioneira de correlacionar a composição química de hornblendas com o grau de metamorfismo da rocha hospedeira, de natureza básica. Segundo esse autor, a principal característica química consiste na substituição de $\mathrm{Si}$ por $\mathrm{Al}$, que está diretamente associada à elevação do gradiente metamórfico da área. Harry (1950), investigando a substituição $\mathrm{Si} / \mathrm{Al}$ em hornblendas de rochas pertencentes às fácies dos xistos verdes, epídoto anfibolito e anfibolito, mostrou que a relação acima também está presente em rochas de outras composições.

Shidô (1958) e Shidô e Miyashiro (1959), com base em dados coligidos nos metabasitos da porção central do Abukuma Plateau, Japão, mencionam também um aumento do teor em álcalis, especialmente $\mathrm{Na}$, com a elevação da temperatura.

$\mathrm{O}$ comportamento crescente do $\mathrm{Ti}$ das hornblendas com o grau de metamorfismo vem sendo observado por inúmeros autores e constitui, segundo Leake (1965a), o índice da maior importância para a avaliação da temperatura de cristalização desses minerais.

Outras mudanças, decréscimo de $\mathrm{FeO}$ e das razões $\mathrm{Fe}_{2} \mathrm{O}_{3} / \mathrm{FeO}$ e $\mathrm{FeO} / \mathrm{MgO}$ com a elevação do gradiente, como sugerido por Engel e Engel (1962b), face à não-confirmação 
por outros autores, parecem destituídas de grande significação, tratando-se aparentemente de variações de caráter mais local, reflexos talvez de heterogeneidade da composição da rocha hospedeira.

Comportamento do alumínio Não obstante Wiseman (1934), Thompson (1947) e Harry (1950) tenham analisado, com o primeiro se atendo mais a anfibólios, o papel assumido pelo alumínio na estrutura dos minerais formadores de rochas, foram Kushiro (1960) e Le Bas (1962) que inicialmente buscaram uma interpretação petrológica para o comportamento desse elemento. Baseando-se em dados estatísticos, referentes a clinopiroxênios de rochas ígneas, esses autores teceram algumas considerações sobre os diversos fatores que controlam a substituição $\mathrm{Si}-\mathrm{Al}$ no magma, terminando por concluir que a proporção de alumínio de coordenação tetraédrica decresce durante o processo de cristalização magmática.

A conclusão acima, aliada ao fato de que actinolita é o principal anfibólio presente no metamorfismo de baixo grau, enquanto que hornblenda ocorre em condições de maior intensidade, bem como em rochas ígneas, levou à crença generalizada na literatura de que o conteúdo de $\mathrm{Al}^{\mathrm{IV}}$ dos anfibólios aumenta com a temperatura de cristalização. Esse fato foi amplamente confirmado por Binns (1965) quando investigando o comportamento das hornblendas do Willyama Complex; porém Engel e Engel (1962b, p. 1 504) referem-se à inexistência de variações significativas na concentração de $\mathrm{Si}$ e $\mathrm{Al}$ com o grau de metamorfismo na área dos Adirondacks.

Mais recentemente, Leake (1965a, b) ocupou-se da análise da coordenação do alumínio em anfibólios. Segundo esse autor, dados relativos a anfibólios, assim como a outros minerais aluminosos, apontam no sentido de que a pressão vigente durante a cristalização é um dos fatores primordiais no estabelecimento da coordenação, com alta pressão favorecendo o maior conteúdo de $\mathrm{Al}^{\mathrm{VI}}$. Leake (1965a, p. $\left.3112-316\right)$ ressalta também que a composição da rocha hospedeira não é menos importante, com a coordenação do alumínio correspondendo a uma expressão combinada desses dois fatores. A utilização desse parâmetro como medida de variação da pressão em regiões metamórficas é, contudo, extremamente difícil, tendo-se em vista que a composição da rocha e do plagioclásio associado, que é relacionada à temperatura, também influencia a concentração do alumínio de coordenação octaédrica.

Em resumo, duas correntes de opinião tentam interpretar a coordenação do alumínio em anfibólios: a primeira liga-a à temperatura, com o conteúdo de $\mathrm{Al}^{\mathrm{IV}}$ crescendo progressivamente com o gradiente metamórfico, enquanto que a segunda vincula-a à pressão e composição da rocha, com o aumento da pressão acarretando maior concentração de $\mathrm{Al}^{\mathrm{VI}}$.

Em se tratando dos anfibólios do Jaraguá, a Fig. 5 parece sugestiva, a despeito da superposição de pontos no intervalo compreendido entre 1,1 e $1,4 \mathrm{Al}^{\mathrm{IV}}$, da maior riqueza em $\mathrm{Al}^{\mathrm{VI}}$ e $\mathrm{Al}^{\mathrm{IV}}$ dos minerais da Zona $\mathrm{B}$, levando, assim, à conclusão de que os mesmos teriam se formado em condições de pressão mais intensa ou, alternativamente, de temperatura mais elevada que os correspondentes da Zona A.

Comportamento dos álcalis Como referido previamente, o teor em álcalis dos anfibólios também constitui um fator de avaliação da intensidade do processo metamórfico. Embora não contestando a validade da relação, Leake (1965a, p. 300) julga-a, no entanto, de maior utilidade junto às rochas anfibolíticas de baixo grau, quando então se processa a transformação de actinolita a hornblenda. 
Engel e Engel (19-2b), analisando o comportamento das hornblendas dos anfibolitos aflorando na porção ocidental dos Adirondacks, encontraram variações concordantes com as de Shidô (1958) e Shidô e Miyashiro (1959) o que também foi notado por Binns (1965) em rochas congêneres do Willyama Complex. A Fig. 3 de Engel e Engel (1962b, p. 1 507), reunindo o número de átomos de $\mathrm{Ca}$ e $(\mathrm{Na}+\mathrm{K})$ por fórmula unitária, realça prontamente a existência de dois agrupamentos, definidos por amostras provenientes das áreas de Emeryville e Colton, exibindo teores mais ou menos constantes em cálcio e bem divergentes em álcalis. Os teores em $(\mathrm{Na}+\mathrm{K})$ aumentam no sentido da área de Colton, em conformidade, assim, com o gradiente metamórfico.

Nos anfibólios do Jaraguá, não foram observadas grandes variações na proporção de álcalis para as duas zonas (Fig. 9), não obstante as composições médias da Tab. IX apontem teores mais elevados em $\mathrm{Na}_{2} \mathrm{O}$ e $\mathrm{K}_{2} \mathrm{O}$ para os minerais da Zona $\mathrm{B}$.

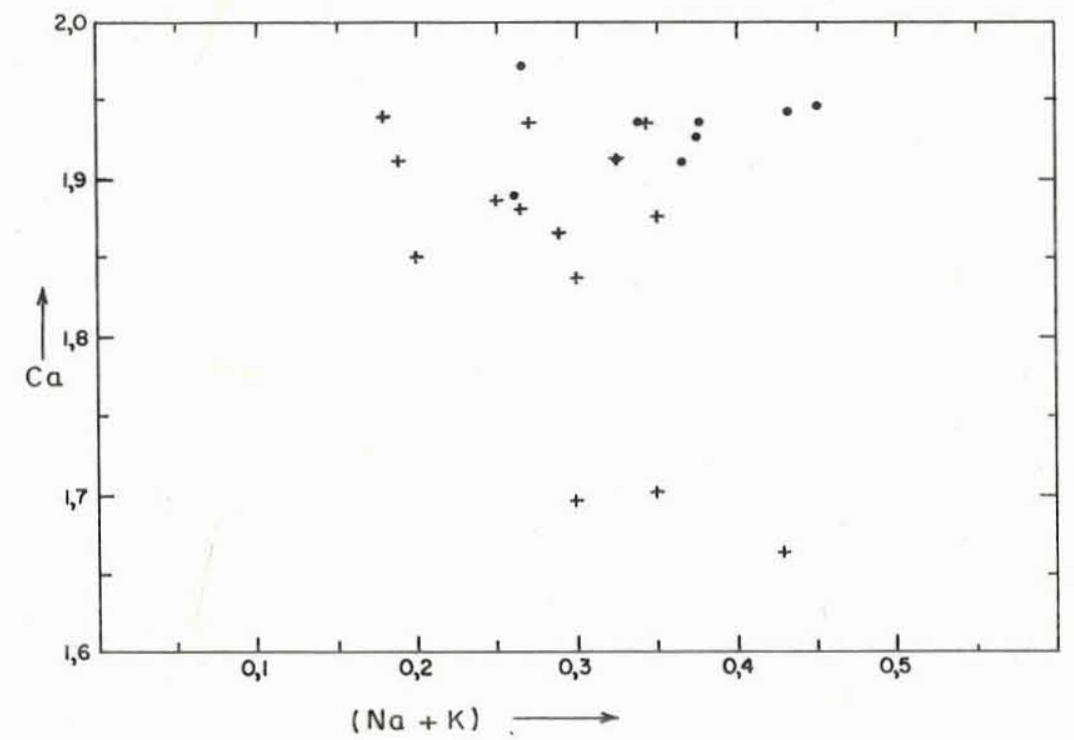

Figura 9-Gráfico relacionando os teores de $\mathrm{Ca}$ e $\mathrm{Na}+\mathrm{K}$ para os anfibólios do Jaraguá. Zona A (+) e Zona B (.)

Comportamento do titânio $\mathrm{O}$ exame de análises químicas de centenas de anfibólios calcíferos e subcalcíferos procedentes de rochas ígneas e metamórficas ensejou a Leake (1965a, p. 301) a conclusão de que a presença de titânio na estrutura desses minerais é controlada principalmente pela temperatura de cristalização, com a concentração daquele elemento crescendo progressivamente com a elevação da temperatura. Esse resultado guarda inteira concordância com as observações feitas por inúmeros autores que indicam ser hornblenda verde a variedade de anfibólio típica de anfibolitos, restringindo-se hornblenda castanha aos anfibolitos de alto grau e granulitos, uma vez que Deer $(1938$, p. 74$)$ estabeleceu há muito tempo que a tonalidade castanha desses minerais é função direta do seu conteúdo em titânio.

No entanto, anteriormente a Leake (1965a), Raychaudhari (1958), Engel e Engel (1962b) e Binns (1965) tiveram a oportunidade de examinar o comportamento do titânio em hornblendas submetidas a condições variáveis de pressão e temperatura, com os resultados apontando sempre no sentido da existência de uma relação sincrônica entre esse elemento e o gradiente metamórfico. Nos Adirondacks, Engel e Engel (1960) verificaram, 
ainda, que o aumento do conteúdo em titânio das hornblendas não é acompanhado pela majoração do teor de $\mathrm{TiO}_{2}$ das rochas anfibolíticas, bem como que a concentração de titânio das biotitas dos gnaisses regionais também cresceu paralelamente à elevação do gradiente metamórfico.

A exemplo de outros anfibolitos, os da região do Jaraguá são portadores de pequena porcentagem de ilmenita, com a sua presença evidenciando que a hornblenda dessas rochas é saturada em óxido de titânio. Nos anfibolitos, de conformidade com Leake (1965a, p. 305), o excesso de óxido de titânio, que não pode ser incorporado pela hornblenda, tende a se cristalizar na forma de ilmenita ou, mais recentemente, como outro mineral titanífero.

Os resultados obtidos por microssonda para os anfibólios em apreço, como visto na Tab. XI e na Fig. 7, são sugestivos, ou seja, de maior riqueza em titânio entre minerais da Zona B. Isso, a despeito de o teor em $\mathrm{TiO}_{2}$ desses anfibolitos ser, em traços gerais, inferior ao das rochas da Zona A (Gomes et al., 1964).

O gráfico reunindo Si e Ti na cela unitária para esses anfibólios, com valores extraídos das Tabs. VIII e X, é fornecido na Fig. 10. Não obstante a superposição parcial dos pontos, a sua distribuição parece indicar que as constantes acima comportam-se inversamente, com os minerais da Zona A exibindo maior concentração em Si e menor em Ti que os da Zona B.

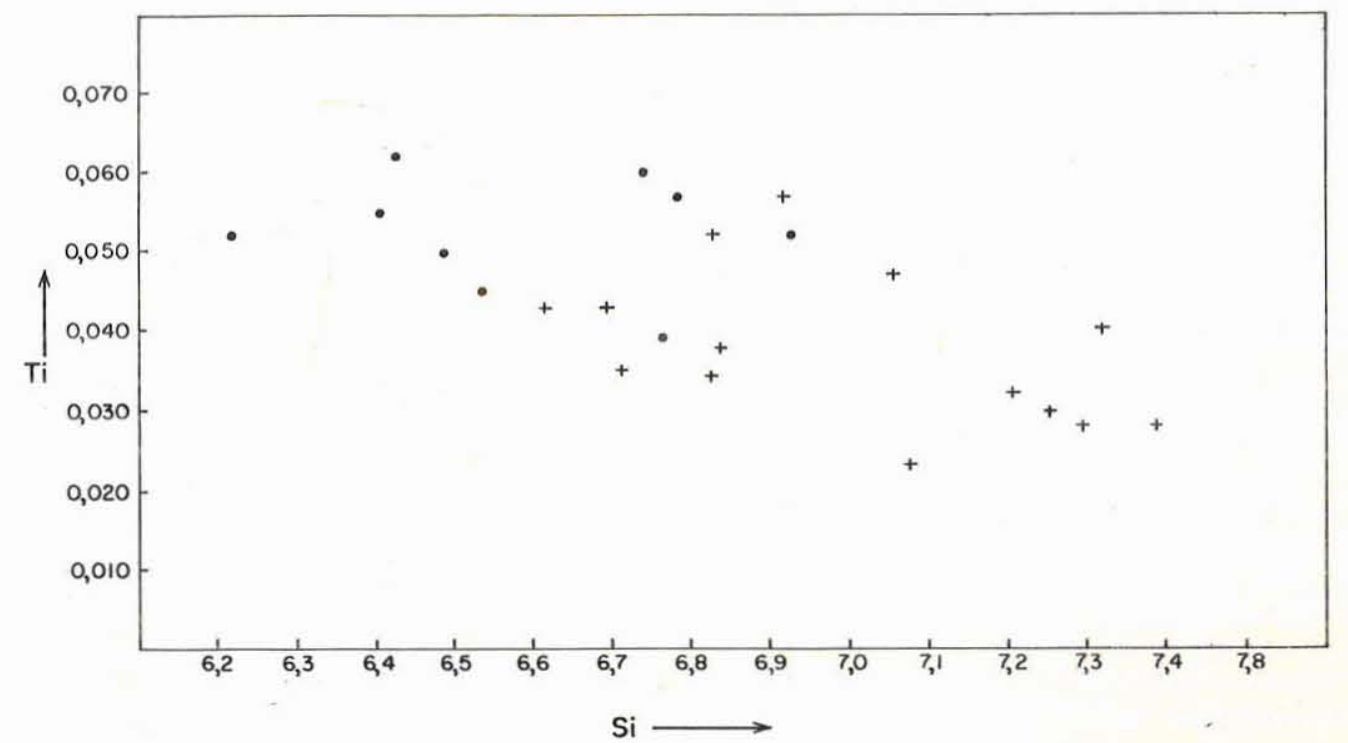

Figura 10 - Relação entre os conteúdos de Ti e Si para os anfibólios do Jaraguá. Zona A (+) e Zona B (.)

Comportamento dos elementos-traços A limitação de informações faz com que o comportamento das hornblendas do Jaraguá seja apenas comparado relativamente àquele dos minerais homônimos dos Adirondacks (Engel e Engel, 1962b) e Black Hills (Raychaudhari, 1958). Uma visão conjunta dos dados reunidos nos três programas é fornecida na Tab. XIII.

Para as hornblendas dos anfibolitos dos Adirondacks e Black Hills, com exceção de $\mathrm{Cu}, \mathrm{Sr}, \mathrm{Y}$ e $\mathrm{Zr}$, os demais elementos apresentam uma distribuição uniforme, com a concentração aumentando paralelamente à elevação da temperatura. Se estes resultados são 
Tabela XIII - Composição química média, elementos traços, de hornblendas

\begin{tabular}{lcccccc}
\hline & \multicolumn{2}{c}{ Jaraguá, SP } & \multicolumn{2}{c}{ Black Hills, South Dakota* } & \multicolumn{2}{c}{ Adirondack Mountains, N.Y.** } \\
& Zona A & Zona B & Lead & NE Lead & Emeryville & Colton \\
\hline & $\begin{array}{c}\text { Almandina } \\
\text { anfibolito }\end{array}$ & $\begin{array}{c}\text { Almandina } \\
\text { anfibolito }\end{array}$ & $\begin{array}{c}\text { Epídoto } \\
\text { anfibolito } \\
\left(400^{\circ} \mathrm{C}\right)\end{array}$ & $\begin{array}{c}\text { Almandina } \\
\text { anfibolito } \\
\left(500^{\circ} \mathrm{C}\right)\end{array}$ & $\begin{array}{c}\text { Almandina } \\
\text { anfibolito } \\
\left(525^{\circ} \mathrm{C}\right)\end{array}$ & $\begin{array}{c}\text { Hornblenda } \\
\text { granulito } \\
\left(625^{\circ} \mathrm{C}\right)\end{array}$ \\
\hline \hline $\mathrm{Cr}$ & 251 & 62 & 102 & 129 & 249 & 737 \\
$\mathrm{~V}$ & 352 & 454 & 185 & 244 & 527 & 811 \\
$\mathrm{Ni}$ & 138 & 92 & 85 & 92 & 57 & 76 \\
$\mathrm{Co}$ & 61 & 68 & 31 & 45 & 47 & 60 \\
$\mathrm{Cu}$ & 19 & 66 & 9 & 10 & 17 & 7 \\
$\mathrm{Sc}$ & 62 & 64 & 29 & 33 & 77 & 109 \\
$\mathrm{Zr}$ & 138 & 42 & 17 & 32 & 97 & 75 \\
$\mathrm{Y}$ & 39 & 67 & 12 & 11 & 72 & 118 \\
$\mathrm{Sr}$ & 56 & 52 & 5 & 31 & 46 & 42 \\
$\mathrm{Ba}$ & 54 & 71 & 9 & 18 & 86 & 106 \\
\hline
\end{tabular}

*Dados extraídos de Raychaudhari (1958)

**Dados extraídos de Engel e Engel (1962b)

confrontados com os referentes às amostras de Jaraguá, verifica-se que V, Ba e Co comportam-se de forma análoga, a despeito de este último exibir tão-somente um leve aumento de concentração junto aos minerais da Zona B.

No tocante aos Adirondacks, Engel e Engel (1962b) atribuem maior significação ao comportamento do $\mathrm{Cr}, \mathrm{V}$ e Sc, enquanto que muito pouco ainda se conhece sobre as hornblendas investigadas por Raychaudhari (1958), bem como sobre os anfibolitos que as contêm.

Evidências texturais Dentro do consenso geral de metamorfismo, principalmente de natureza dinamotermal, atribui-se à variação crescente da granulação dos constituintes minerais um caráter diagnóstico da elevação do grau de metamorfismo. Essa relação encontra confirmação em numerosas ocorrências de rochas anfibolíticas, em que anfibólios foram submetidos a mudanças nas condições de pressão e temperatura.

No caso particular do Jaraguá, esse fato foi igualmente registrado, pois os anfibólios da Zona B possuem dimensões maiores que os homônimos da Zona A.

A estrutura zonada presente em vários desses anfibólios, com as partes centrais dos cristais constituídas de actinolita, enquanto que as bordas têm composição mais rica em hornblenda, poderia também ser tomada como feição sugestiva de elevação do gradiente metamórfico, visto que a primeira espécie mineralógica tem sua formação restrita apenas ao metamorfismo de baixo grau, mais compatível com a fácies dos xistos verdes.

Considerações sobre o processo metamórfico Dados fornecidos em Gomes et al. (1964, p. 670) são indicativos de que os anfibolitos do Jaraguá possuem composição química inicial heterogênea, com a principal diferença residindo no teor de $\mathrm{MgO}$. Outras diferenças observadas, como nas concentrações de $\mathrm{SiO}_{2} \mathrm{CaO}, \mathrm{Na}_{2} \mathrm{O}$ e $\mathrm{H}_{2} \mathrm{O}$, poderiam estar ligadas ao processo metamórfico, não constituindo necessariamente um reflexo direto da sua composição original.

Acredita-se que o teor mais alto em $\mathrm{SiO}_{2}$ das amostras localizadas na porção sul-sudeste do corpo seja resultante de ação metassomática causada pelo maciço granítico da Cantareira, uma vez que este, em áreas adjacentes à do Jaraguá, é o agente responsável 
por intensa pneumatólise dos metassedimentos ençaixantes. A presença de turmalina em alguns desses anfibolitos poderia ser tomada como evidência sugestiva daquele fenômeno.

Por sua vez, o comportamento de $\mathrm{H}_{2} \mathrm{O}$, com a sua concentração diminuindo concomitantemente à elevação da temperatura, é similar ao observado por Miyashiro (1958) e Engel e Engel (1962a) para outras ocorrências, constituindo, de conformidade com Miyashiro (1968), feição característica do metamorfismo progressivo de anfibolitos.

$\mathrm{O}$ teor variável em $\mathrm{MgO}$ dos anfibolitos, com os situados na porção centro-oeste do corpo mostrando maior concentração, parece ser o fator responsável pelas flutuações químicas processadas na composição das hornblendas, uma vez que estas são mais magnesianas nas rochas dessa área. Por outro lado, as variações encontradas para $\mathrm{CaO}$ e $\mathrm{Na}_{2} \mathrm{O}$, com os anfibolitos aflorando na região sul-sudeste do corpo exibindo maior riqueza em $\mathrm{CaO}$ e menor em $\mathrm{Na}_{2} \mathrm{O}$, refletem principalmente a natureza dos seus plagioclásios.

Conquanto os anfibolitos tenham reagido da maneira distinta às modificações ocorridas nas condições metamórficas, como evidenciado pela presença das duas zonas petrográficas dentro do corpo, pouco ainda se conhece sobre o comportamento de seus minerais, pois as informações necessárias à formação de uma base de discussão das prováveis mudanças de sua composição ainda são insuficientes. Julga-se, no entanto, que a maior porcentagem de feldspatos e a menor de anfibólios nas variedades da Zona B refletem a adaptação dessas rochas ao ambiente de maior temperatura, desconhecendo-se, contudo, a extensão do fenômeno. Essa conclusão e a que confere natureza mais cálcica aos plagioclásios dessa área do corpo guardam total concordância com as alcançadas por Engel e Engel (1962a) nos Adirondacks.

Sem, contudo, aproximar-se do estádio de metamorfismo atingido pelos anfibolitos dessa última região, de condições compatíveis à fácies hornblenda granulito, não se processando, por conseguinte, a formação de clinopiroxênios, o desaparecimento da titanita, etc., nota-se a existência da estreita correspondência quanto ao sentido evolutivo dessas alterações. Nos anfibolitos do Jaraguá, elas culminam com a diminuição dos teores de anfibólios e epídotos e subseqüente aumento da concentração de feldspatos e do seu teor em cálcio, em adição à maior granulação dos minerais, junto às amostras da Zona B.

A despeito do aparente ajustamento dos minerais à distribuição zonal de temperatura, existem evidências, traduzidas na variação extrema da composição dos feldspatos e na estrutura zonada dos cristais de anfibólios, de que deixaram de atingir condições de completo equilíbrio. A primeira transformação mineralógica encontra justificativa no papel desempenhado pelo epídoto, que se enriquece mais nas amostras portadoras de plagioclásio com menor porcentagem de molécula de anortita, confirmando assim as conclusões teóricas, altamente difundidas na literatura, de que o comportamento desses minerais é controlado pela reação: plagioclásio mais sódico + epídoto $\longrightarrow$ plagioclásio mais cálcico.

A transformação actinolita $\longrightarrow$ hornblenda é conceitualmente mais controvertida e constitui uma feição textural relativamente comum nos anfibolitos associados ao Grupo São Roque-Açungui. Nos cristais zonados, os dados analíticos obtidos demonstram que as suas porções centrais possuem composição mais actinolítica, enquanto que hornblenda corresponde a variedades periféricas. Considerando a paragênese clássica desses anfibólios calcíferos, em que actinolita se forma no processo dinamotermal em condições compatíveis à fácies dos xistos verdes, e hornblenda, à fácies almandina anfibolito, poder-se-ia assumir que os anfibolitos do Jaraguá foram, posteriormente à sua formação, submetidos a condições de temperatura mais alta. Essa elevação do gradiente térmico, ao que tudo indica causada pela intrusão do maciço da Cantareira, tem assim na estrutura zonada a sua feição reliquiar junto a esses anfibolitos, uma vez que em diversas amostras existiram condições favoráveis à total homogeneização dos minerais. 
Uma segunda interpretação para o zoneamento poderia ser a sugerida por Dodge (1942). De conformidade com esse autor, a formação de hornblendas nos anfibolitos da área de Lead processou-se na sua primeira fase às expensas da augita da rocha original, enquanto que o crescimento posterior durante o metamorfismo teve lugar a partir do feldspato, dando com isso uma hornblenda mais aluminosa. Conquanto essa idéia pudesse ser também aplicável aos anfibólios do Jaraguá, a primeira hipótese parece mais aceitável tendo-se em vista a existência de diversas feições apontando no sentido de dois eventos metamórficos, o segundo de temperatura mais elevada.

Agradecimentos Agradecimentos são consignados ao Conselho Nacional de Pesquisas pela concessão do auxílio financeiro (Proc. 12883/69, T.C. 11761 ), que permitiu a realização desta pesquisa. Os autores são também gratos ao Dr. Jacques Delhal, do Musée Royale de l'Afrique Centrale, Tervuren, Bélgica, pela colaboração prestada no programa com a fluorescência de raios X.

\section{BIBLIOGRAFIA}

BINNS, R. A. - 1965 - The mineralogy of metamorphosed basic rocks from the Willyama Complex, Broken Hill District, New South Wales. Part I. Hornblendes. Mineral. Mag., 35: 306-326

BROWN, F. e CARMICHAEL, I. S. E. - 1969 - Lithos. Referência constante dos arquivos do Laboratório de "Electron Microprobe" da Universidade da Califórnia, Berkeley

COLEMAN, R. G. - 1961 - Jadeite deposits of the Clear Creek area, New Idria district, San Benito County, California, J. Petrol., 2: 209-247

CORDANI, U. G., ROCHA-CAMPOS, A. C., DAVINO, A. e BJÖRNBERG, A. - 1961 - Geologia da região do Jaraguá. Soc. Bras. Geol., 10: 73-94

COUTINHO, J. M. V. - 1955 - Metaconglomerado e rochas associadas no Município de São Paulo. Fac. Fil. Ciên. Letras, 186, Mineralogia, 13: 5-57

DEER, W. A. - 1938 - The composition and paragenesis of the hornblendes of the Glen Tilt complex, Perthshire. Mineral. Mag., 25: 56-74

DEER, W. A., HOWIE, R. A. e ZUSSMAN, J. - 1963 - Rock forming minerals vol. 2. Chain silicates, Longmans, London

DODGE, T.A. - 1942 - Amphibolites of the Lead Area, Northern Black-Hills, South Dakota, Geol. Soc. Amer. Bull., 53: 561-584

ENGEL, A. E. J. e ENGEL, C. G. - 1960 - Progressive metamorphism and granitization of the major paragneiss, northwest Adirondack Mountains, New York. Part 2, Mineralogy. Geol. Soc. Amer. Bull., 71: pp. 1-58

ENGEL, A. E. J. e ENGEL, C. G. - 1962a - Progressive Metamorphism of Amphibolite, Northwest Adirondack Mountains, New York. Geol. Soc. Amer., Buddington Volume, pp. 37-82

ENGEL, A. E. J. e ENGEL, C. G. - 1962b - Hornblendes formed during progressive metamorphism of amphibolites, Northwest Adirondack Mountains, New York, Geol. Soc. Amer. Bull., 73: 1499-1 514

FLANAGAN, F. J. - 1969 - U.S. Geological Survey Standards-II. First Compilation of data for the new U.S.G.S. rocks. Geochim. et Cosmochim. Acta, 33: 81-120

FRAZER, J. Z., FITZGERALD, R. W. e REID, A. M. - 1966 - Computer programs EMX and EMX 2 por electron microprobe data processing (inédito)

GOMES, C. G. - 1962 - Contribuição ao conhecimento dos anfibolitos da regiào do Jaraguá, SP. Soc. Bras. Geol., 11: 57-78

GOMES, C. G. - 1971 - Polimetamorfismo dos anfibolitos do Jaraguá, São Paulo: Evidências, químicas, mineralógicas e texturais. Tese Livre Docência. Instituto de Geociências, Universidade de São Paulo (inédito)

GOMES, C. G. - no prelo - Chemical changes in plagioclases and their bearing on the petrologic history of an amphibolite body. Amer. Mineral

GOMES, C. B., SANTINI, P. e DUTRA, C. V. - 1964 - Petrochemistry of a Precambrian amphibolite from the Jaraguá Area, São Paulo, Brazil, J. Geol., 72: 664-680 
GOMES, C. B., DUTRA, C. V. e OOSTERWYGK-GASTUCHE, M. C. - 1968 - Variações químicas nas hornblendas do corpo anfibolítico do Jaraguá, SP. XXII Congr. Bras. Geol., Resumo Comunicações, p. 4

HALLIMOND, A. F. - 1943 - On the graphical representation of the calciferous amphiboles. Amer. Mineral., 28: 65-89

HARRY, W. T. - 1950 - Aluminum replacing silicon in some silicate lattices. Mineral. Mag., 29: 142-149

HERZ, N. e DUTRA, C. V. - 1960 - Minor element abundance in part of the Brazilian Shield. Geochim. et Cosmochim. Acta, 21: 81-98

KUSHIRO, I. - $1960-\mathrm{Si}-\mathrm{Al}$ relations in clinopyroxenes from igneous rocks. Amer. J. Sci., 258 : 548-554

LE BAS, M. J. - 1962 - The role of aluminium in igneous clinopyroxenes with relation to their parentage. Amer. J. Sci., 260: 267-288

LEAKE, B. E. - 1965a - The relationship between composition of calciferous amphibole and grade of metamorphism in Controls of Metamorphism, pp. 299-318. Ed. W. S. Pitcher e G. W. Flinn. Oliver and Boyd, Edinburgh

LEAKE, B. E. - 1965b - The relationship between tetrahedral aluminum and the maximum possible octahedral aluminum in natural calciferous and subcalciferous amphiboles. Amer. Mineral., 50: $843-851$

LEAKE, B. E. - 1968 - A Catalog of Analyzed Calciferous and Subcalciferous Amphiboles together with their Nomenclature and Associated Minerals. Geol. Soc. Amer. Sp. Paper, 98: 1-210

MIYASHIRO, A. - 1958 - Regional metamorphism of the Gosaisyo-Takanuki district in the central Abukuma Plateau. Univ. Tokyo, J. Fac. Sci., sec. 2, 11: 219-272

MIYASHIRO, A. - 1968 - Metamorphism of Mafic Rocks in Basalts, vol. 2, pp. 799-834. Ed. H. H. Hess e A. Poldervaart. Interscience Publishers

RAYCHAUDHARI, B. - 1968 - Ph. D. thesis, Calif. Inst. Technology. Citação em Engel e Engel. (1962b, pp. 1510-1513)

RIMSAITE, J. H. Y. - 1964 - Beitr. Mineral. Petrol., 10: 152-183. Referência constante dos arquivos do Laboratório de "Electron Microprobe" da Universidade da Califórnia, Berkeley

SHAW, D. M. - 1960 - The geochemistry of scapolite. Part II. Trace elements, petrology and general geochemistry. J. Petrol., 1: 261-285

SHIDÔ, F. - 1958 - Plutonic and metamorphic rocks of the Nakoso and Iritono districts in the central Abukuma Plateau. Univ. Tokyo, J. Fac. Sci., sec. 2, 11: pp. 131-217

SHIDÔ, F. e MIYASHIRO, A. - 1959 - Hornblendes of basic metamorphic rocks. Univ. Tokyo, J. Fac. Sci., sec. 2, 12, pp. 85-102

THOMPSON, J.B., JR. - 1947 - Role of aluminum in the rock-forming silicates. Geol. Soc. Amer. Bull., 58, p. 1232

TURNER, F. J. e VERHOOGEN, J. - 1960 - Igneous and metamorphic petrology. McGraw-Hill, New York

WARREN, B.E. - 1930 - The crystal structure and chemical composition of the monoclinic amphiboles. Zeit. Krist., 72: pp. 482-517

WISEMAN, J. B. H. - 1934 - The central and south-west highland epidiorites: a study in progressive metamorphism. Quart. J. Geol. Soc. London, 90, pp. 354-417 